\title{
Emotional language processing in autism spectrum disorders: a systematic review
}

\author{
Alina Lartseva ${ }^{1,2 *}$, Ton Dijkstra ${ }^{3}$ and Jan K. Buitelaar ${ }^{1}$ \\ ' Department of Cognitive Neuroscience, Donders Centre for Neuroscience, Radboud University Medical Centre, Nijmegen, Netherlands \\ ${ }^{2}$ International Max Planck Research School for Language Sciences, Max Planck Institute for Psycholinguistics, Nijmegen, Netherlands \\ ${ }^{3}$ Donders Centre for Cognition, Radboud University Nijmegen, Nijmegen, Netherlands
}

Edited by:

Sophie Molholm, Albert Einstein

College of Medicine, USA

Reviewed by:

Sebastian B. Gaigg, City University London, UK

Alice Brown Brandwein, The Child

Mind Institute, USA

*Correspondence:

Alina Lartseva, Department of

Cognitive Neuroscience, Donders

Centre for Neuroscience, Radboud

University Medical Centre,

Kapittelweg 29, 6525 EZ Nijmegen, Netherlands

e-mail:a.lartseva@donders.ru.nl
In his first description of Autism Spectrum Disorders (ASD), Kanner emphasized emotional impairments by characterizing children with ASD as indifferent to other people, selfabsorbed, emotionally cold, distanced, and retracted. Thereafter, emotional impairments became regarded as part of the social impairments of ASD, and research mostly focused on understanding how individuals with ASD recognize visual expressions of emotions from faces and body postures. However, it still remains unclear how emotions are processed outside of the visual domain. This systematic review aims to fill this gap by focusing on impairments of emotional language processing in ASD. We systematically searched PubMed for papers published between 1990 and 2013 using standardized search terms. Studies show that people with ASD are able to correctly classify emotional language stimuli as emotionally positive or negative. However, processing of emotional language stimuli in ASD is associated with atypical patterns of attention and memory performance, as well as abnormal physiological and neural activity. Particularly, younger children with ASD have difficulties in acquiring and developing emotional concepts, and avoid using these in discourse. These emotional language impairments were not consistently associated with age, IQ, or level of development of language skills. We discuss how emotional language impairments fit with existing cognitive theories of ASD, such as central coherence, executive dysfunction, and weak Theory of Mind. We conclude that emotional impairments in ASD may be broader than just a mere consequence of social impairments, and should receive more attention in future research.

Keywords: autism spectrum disorders, asperger syndrome, social, emotion, affect, language

\section{INTRODUCTION}

Autism spectrum disorder (ASD) is characterized by persistent impairments in social communication and interaction, restricted and repetitive behavior, and an onset of the disorder in early childhood (APA, 2013). While ASD was divided into subtypes in previous versions of the diagnostic and statistical manual of mental disorders (DSM), different forms of ASD are now combined in one broad category in the new DSM-5 (APA, 2013).

Clinically important diagnostic characteristics of ASD include lack of spontaneous seeking to share enjoyment, emotions, affect, interests, or achievements with other people, and a lack of emotional reciprocity. In his original description of autism,

\footnotetext{
Abbreviations: ABC, Autism Behavior Checklist; ADI, Autism Diagnostic Interview; ADOS, Autism Diagnostic Observation Schedule; AS, Asperger syndrome; ASD, Autism Spectrum Disorder; ASDS, Asperger Syndrome Diagnostic Scale; CA, chronological age; CARS, Childhood Autism Rating Scale; DD, developmental delay; DS, Down syndrome; LFA, low-functioning autism; MA, mental age; NVIQ, nonverbal intelligence quotient; NVMA, nonverbal mental age; PDD, Pervasive Developmental Disorder; PIQ, Performance intelligence quotient; TD, typically developing; VIQ, verbal intelligence quotient; VMA, verbal mental age; WS, Williams syndrome.
}

Kanner (1943) already emphasized the presence of emotional impairments, and characterized the patients as indifferent to other people, self-absorbed, emotionally cold, distanced, and retracted. However in the later years these emotional impairments were shifted to the background and were considered to be just a part of the core social deficits (Ritvo and Freeman, 1977; Rutter, 1978; Denckla, 1986; Fein et al., 1986). Most studies of emotion processing in ASD focused on facial emotion recognition (Jemel et al., 2006; Harms et al., 2010; Uljarevic and Hamilton, 2013). A recent meta-analysis concluded that facial emotion recognition is indeed impaired in the ASD population, although there is considerable variability between studies and the true effect size is probably much smaller due to publication bias (Uljarevic and Hamilton, 2013). However, the evidence from studies with facial stimuli alone is not sufficient to draw conclusions about the severity and extent of emotional impairments in ASD. The reason is that individuals with ASD have problems with processing faces in general, not restricted to only emotional faces (Jemel et al., 2006; Harms et al., 2010). In contrast to typical individuals, individuals with ASD do not spontaneously pay attention to faces, ignore the eye region and focus on less 
significant parts of the face (Jemel et al., 2006; Wolf et al., 2008; Senju and Johnson, 2009). So, even in studies that do report main group effects in facial emotion recognition, it is unclear whether the differences should be explained by a more specific emotional impairment, or by more general problems in face processing.

Comparatively little attention has been paid in research in ASD to processing of other types of emotional stimuli, such as emotional language (understanding of emotion-laden words, sentences and text; talking about emotions; perception and production of emotional intonation in speech). In fact, a lack of research on emotion processing in non-social tasks has been pointed out in earlier reviews (Gaigg, 2012; Nuske et al., 2013). If more generic emotional impairments exist in people with ASD that cause facial emotion processing deficits, we would expect to observe emotional impairments in language as well. The aim of this article is to provide a systematic review of the empirical literature with respect to emotional language in ASD, discuss the implications for our understanding of ASD, and give recommendations for future research.

In discussing emotional language in ASD it is important to keep in mind that many people with ASD have problems in language development and impairment in verbal and nonverbal communication. Phenotypically, most people with ASD have semantic, syntactic and pragmatic deficits, and a smaller number are known to have phonological deficits (Groen et al., 2008). On the most high-functioning end of the autism spectrum, people have no apparent language delay and normal to high verbal IQ with only minor difficulties with respect to pragmatic language use. In contrast, individuals on the most lowfunctioning end never develop any language at all. The majority of people with ASD range between these two extremes. This variation in verbal ability can be a major confound. Possible ways to deal with it include: (1) comparing high-functioning people with ASD to healthy controls matched on verbal IQ; (2) comparing people with ASD to other clinical groups with a similar level of language problems (for example, suffering from dyslexia or specific language impairment); and (3) including participants with a wide range of verbal abilities and testing if correcting for verbal IQ causes the effect of emotion to disappear.

\section{AIM}

There is an evident lack of knowledge on how individuals with ASD process non-facial emotional stimuli, such as language. This paper aims to fill this gap by providing a systematic review of emotional impairments in ASD with a primary focus on emotional language. We will address the following questions:

1. Is there evidence for emotional impairments in the language domain? Is it present in different experimental paradigms? Does it depend on modality, such as visual (i.e., reading words and texts) or auditory channel (i.e., listening to words and sentences), and/or on complexity of information: simple (single words) vs. complex (sentences and discourse)? Does it affect primarily implicit measures (which the participant is not aware of or is not able to exert conscious control: difference in memory performance, error rates, physiological responses) or explicit processing of emotion (valence rating, verbal report)?

2. Does the degree of emotional language impairments in ASD individuals correlate with their clinical characteristics, such as the severity of cognitive and clinical linguistic impairments? If emotional impairments are caused by a linguistic or cognitive impairment, one would expect emotional impairments to be present more often and with greater severity in individuals with lower verbal or nonverbal IQ and a history of intellectual and language delay. In addition, IQ then would be negatively correlated with the severity of emotional impairments.

3. How do emotional language impairments fit within existing cognitive theories of ASD, such as the central coherence impairment, executive dysfunction, Theory of Mind account, and impairment of the mirror neuron system (MNS)? We will also explore whether the concept of alexithymia and motivational factors related to reward and punishment learning provide useful theoretical accounts of emotional language impairments in subjects with ASD.

\section{METHODS}

To identify relevant articles, we systematically searched PubMed and Google Scholar for papers published from 1980 onwards using the following search terms: \#1 autism OR autistic OR Asperger OR ASD; \#2 emotion* OR affect OR feeling; \#3 \#1 AND $\# 2$. We selected all original studies that compared the performance of a group of people diagnosed with ASD with controls on an emotion-related measure. Additionally, we manually searched the reference lists of these papers, and checked (using Google Scholar) all articles that were cited in the articles we selected.

Articles were included in our systematic review if they satisfied the following criteria:

- inclusion of participants with ASD diagnosed according to the official DSM or international classification of diseases (ICD) criteria;

- inclusion of at least one control group without ASD;

- the groups were compared with respect to their performance on an emotion-related measure, and either considered emotionally laden stimuli as an independent variable (such as emotional words, sentences or prosody) or studied the spontaneous production of emotionally loaded reactions (such as referring to one's own or another person's emotional state).

We excluded studies focusing on the processing of facial expressions of emotions, because these have been extensively reviewed elsewhere (Jemel et al., 2006; Harms et al., 2010), as well as intervention and drug studies. If the study measured multiple variables, performance on facial emotion recognition was not reviewed but other relevant outcomes were reported in the review. Thus, in contrast to other reviews, we focused exclusively on studies of relatively abstract emotional representations. At the end, we retrieved 33 studies with verbal/linguistic stimuli to be discussed in this review. A summary of all papers can be found in Table 1 including details on the ASD and control groups and the tasks administered. The studies retrieved vary with 8 reporting on emotional processing in children, 15 in adolescents, 
and 10 in adults with ASD. Nineteen/thirty three (57 percent) of the studies used formal research instruments autism diagnostic interview (ADI) or autism diagnostic observation schedule (ADOS) to confirm clinical diagnosis. Other diagnostic instruments included Autism Behavior Checklist (Volkmar et al., 1988), Asperger syndrome diagnostic scale (Goldstein, 2002), childhood autism rating scale (Schopler et al., 1980; Rellini et al., 2004), social communication questionnaire (Chandler et al., 2007), and others. Sample sizes for most studies were rather small (on average 18 participants in the ASD group, ranging from 6-37 participants) with only $12(1 / 3)$ studies reporting about sample sizes larger than 20. Twenty-five studies included higher functioning subjects with ASD, whereas 8 studies investigated lower functioning participants. Seventeen studies did match ASD and control group on age and verbal/nonverbal IQ, but in 5 studies the groups significantly differed on IQ scores, 6 studies did not provide IQ scores for the control group, and 5 studies included multiple control groups partially matched on chronological age, mental age and IQ.

\section{IS THERE EVIDENCE FOR EMOTIONAL IMPAIRMENT IN EMOTIONAL LANGUAGE?}

First, we addressed the question of whether abnormalities in emotional language processing are specific to particular cognitive domains, or are more general, i.e., independent of the type of information involved. In the next section, we group all articles in terms of the cognitive task used.

\section{COMPARISON OF DIFFERENT TASKS}

Emotional language has been investigated in a variety of tasks including recognition and recall, stimulus detection, and discourse and reasoning.

Typically developing people remember emotion laden words and sentences better than neutral stimuli (Dolcos et al., 2004). Some reports indicate that this is not the case for subjects with ASD. In one study, participants listened to and had to memorize neutral and emotional sentences, among other conditions (Beversdorf et al., 1998). Memory performance did not differ between ASD and control participants on scrambled word lists, neutral sentences, sentences which made a coherent story together with other sentences from the list, and sentences describing other people's mental states and perspectives. The only difference between the two groups was on recall of emotional sentences where typical participants showed better performance compared to other conditions, while ASD subjects did not (Beversdorf et al., 1998). A similar finding was obtained in studies with visually presented single words (Kennedy et al., 2006; Gaigg and Bowler, 2008, 2009b). Control participants showed better recognition memory for emotional words compared to neutral words, had better recall rates for emotion words over a $24 \mathrm{~h}$ period, and were less likely to falsely recall them in an illusory memory paradigm. In ASD subjects, however, those effects were significantly diminished. The current view is that typical people remember emotional stimuli better because they perceive these stimuli as potentially motivationally significant and allocate additional processing resources. This process is subserved by medial temporal lobe structures and results in better encoding and retrieval (Dolcos et al., 2004).
Lack of emotional memory effect in the ASD participants can mean that they either did not perceive the emotional words or sentences as more salient and motivationally relevant, or failed to efficiently encode them because of an impairment at a later processing stage. In contrast, another study did not find a difference in memory performance for emotion words between ASD and typical participants (South et al., 2008). In this study participants read word lists and were then immediately tested for recognition memory. This result suggests that the differences between the ASD and typical groups on emotional memory could be dependent on time and could be less prominent at immediate recall/recognition.

Subjects with ASD also display abnormalities in their automatic attentional reaction to emotionally salient stimuli. In an attentional blink paradigm, subjects were asked to read words in a rapid serial visual presentation (RSVP) stream and detect target words printed in a red color (Gaigg and Bowler, 2009a). Normally, the probability of successfully detecting a target word depends on the time interval between the presentation of the preceding target word (T1) and the current target word (T2). If the $\mathrm{T} 1$ was presented just before the $\mathrm{T} 2$, then at the time the $\mathrm{T} 2$ is presented most of the attention resources are still engaged in processing the $\mathrm{T} 1$, and therefore the probability of successfully detecting T2 significantly drops ("attentional blink" effect). However, this attentional blink phenomenon does not occur with emotional words, which are detected with high accuracy irrespective of the timing. This emotional modulation of attentional blink is thought to be a result of emotion words being perceived as more salient and motivationally relevant and thus receiving more attentional resources, primarily because if the involvement of the amygdala in detecting of emotional words (Anderson and Phelps, 2001). In two studies, the predicted modulation of attentional blink by $\mathrm{T} 2$ valence was found in controls, but not in ASD. In the ASD group, the detection rates of neutral and emotional T2s were not statistically different (Corden et al., 2008; Gaigg and Bowler, 2009a). This result suggests that individuals with ASD do not perceive emotional words as more salient, suggesting an impairment in the amygdala functioning or in the connectivity between the amygdala, cingulate cortex and frontal cortical areas in the ASD group (Gaigg and Bowler, 2009a).

Studies of reasoning about emotions expressed in discourse also showed differences between ASD and control individuals. One study investigated children's responses in a structured conversation. This study found that children with Asperger syndrome more frequently gave inadequate or no response when talking about an emotional topic compared to a neutral one (Adams et al., 2002). Two more studies investigated emotion word use during telling a story about a fictional or real event. They found that children with ASD talked significantly less about emotions, desires and beliefs compared to typically developing control children. Children with ASD also less frequently referred to emotional states as a cause of one's action (compared to TD group), although both groups talked equally often about causes for physical events (Capps et al., 2000; Losh and Capps, 2006). Similar results were obtained in a study which asked adult participants to watch a film clip displaying interactions 


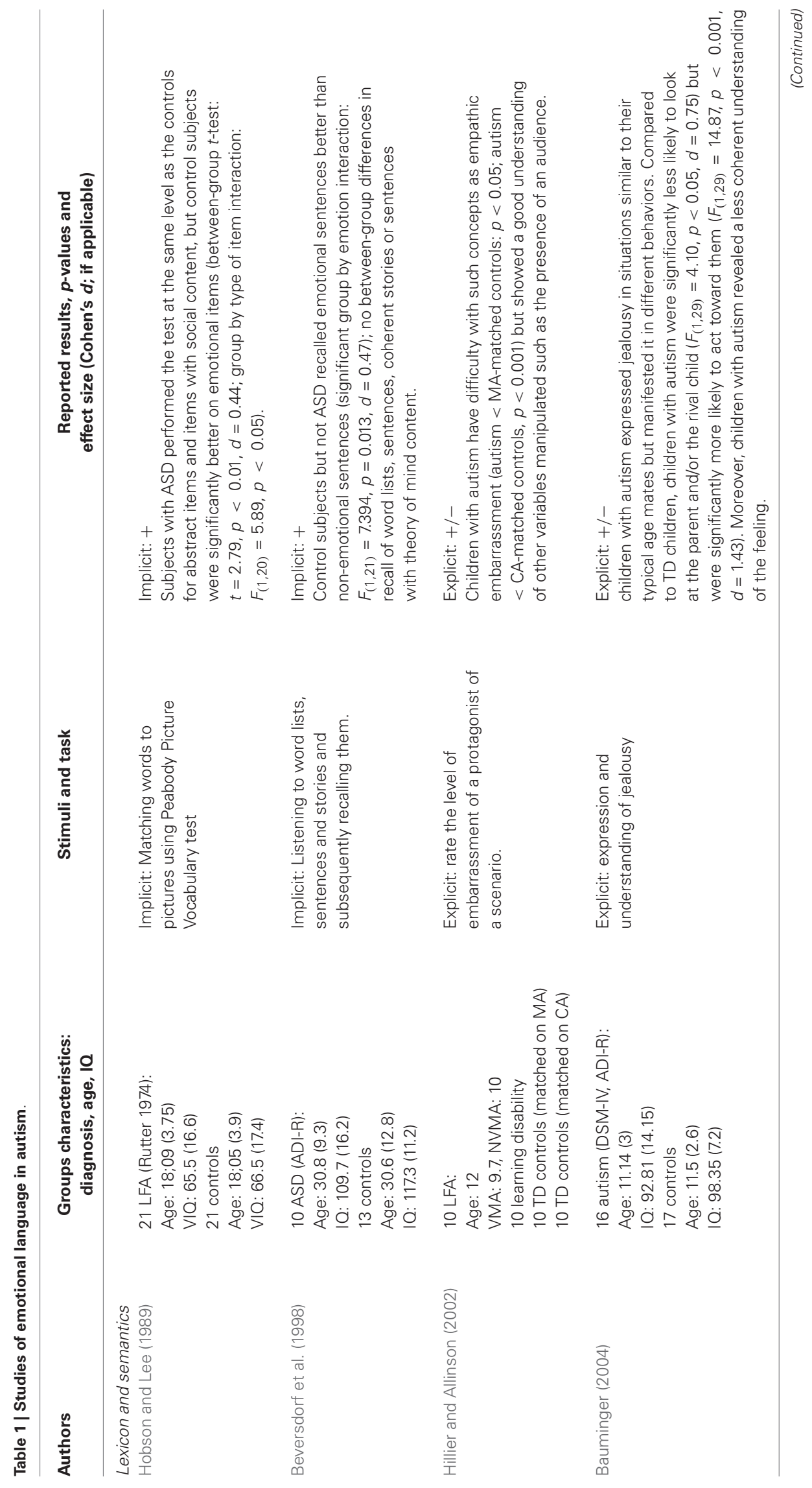




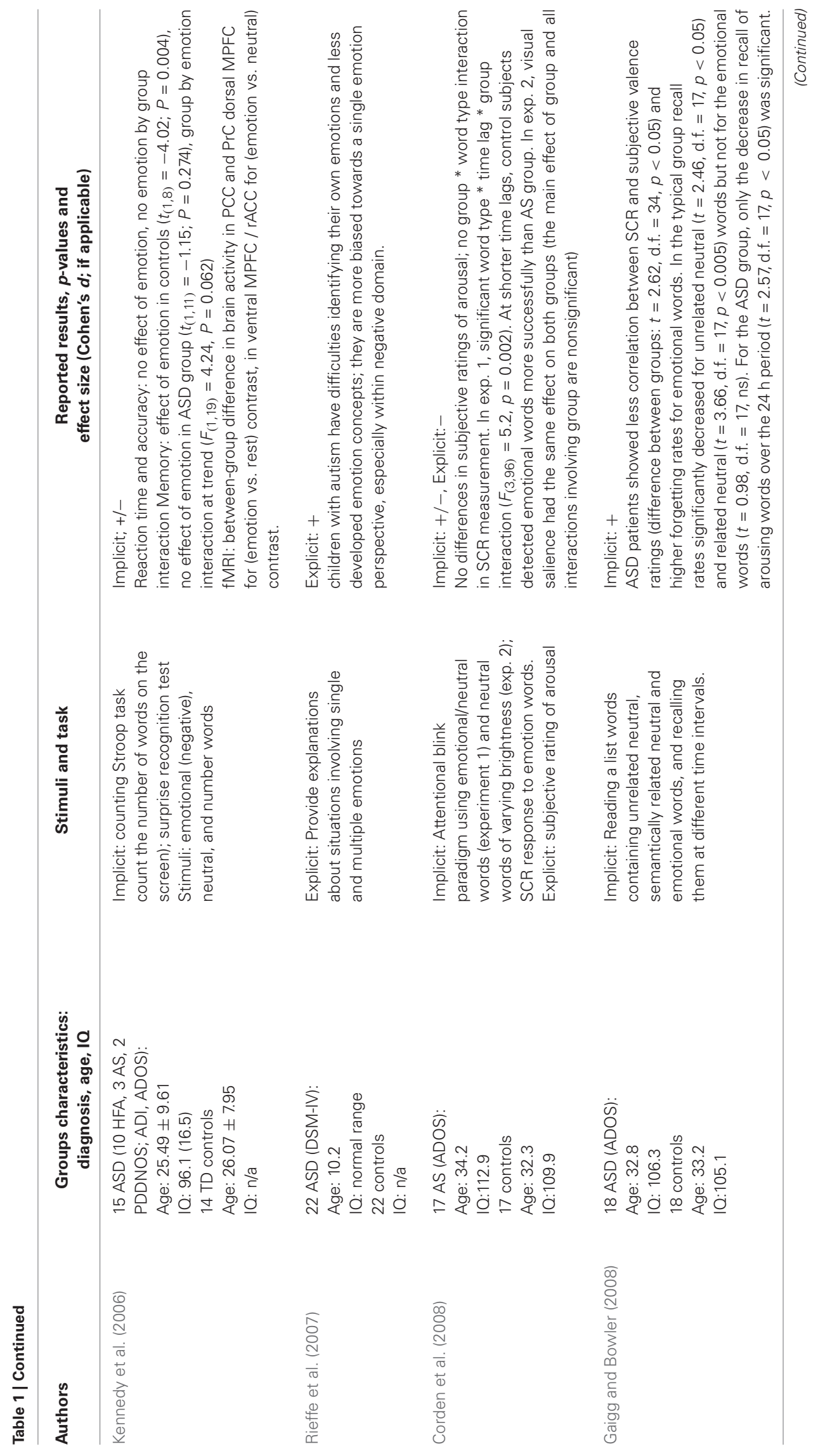




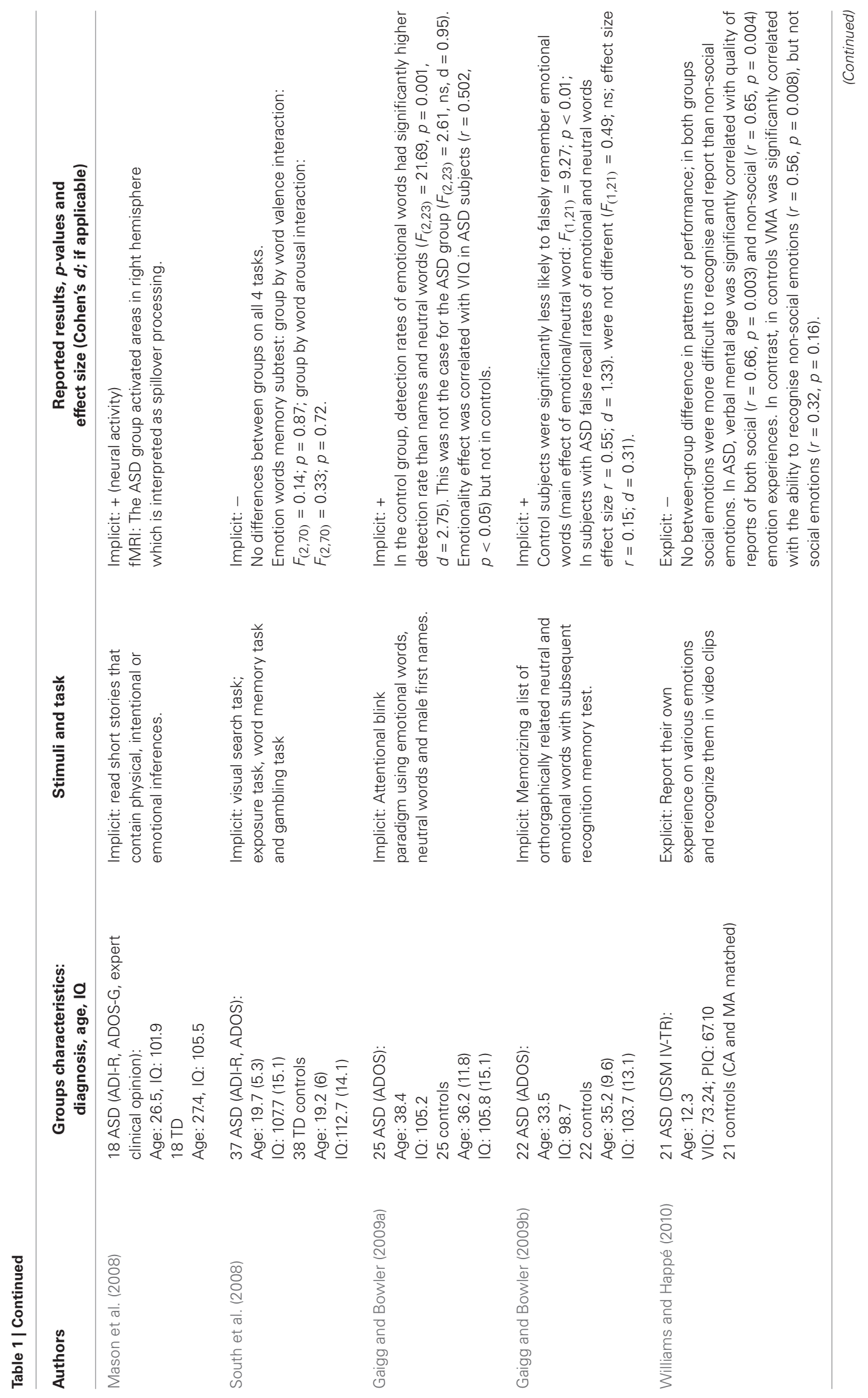




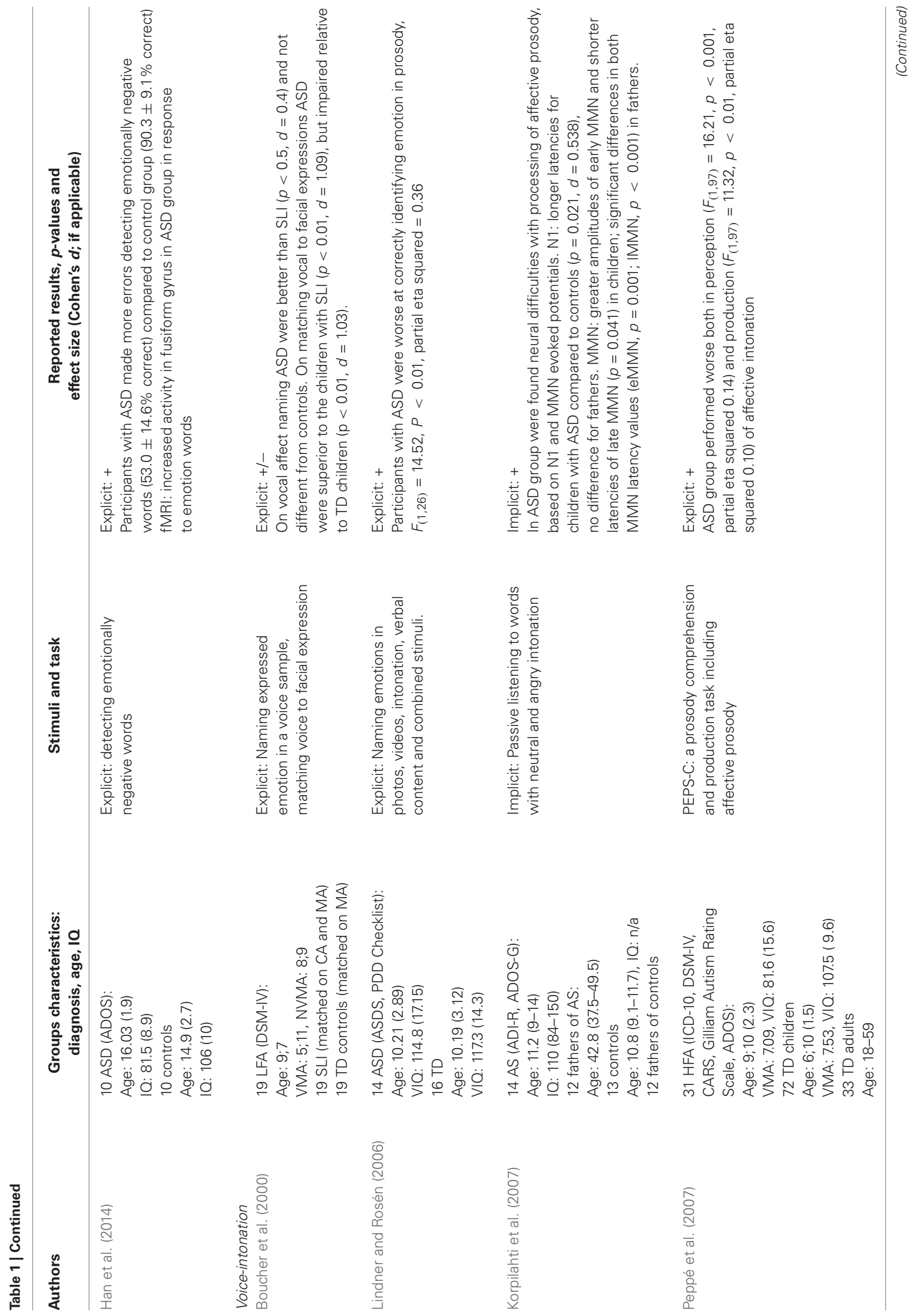




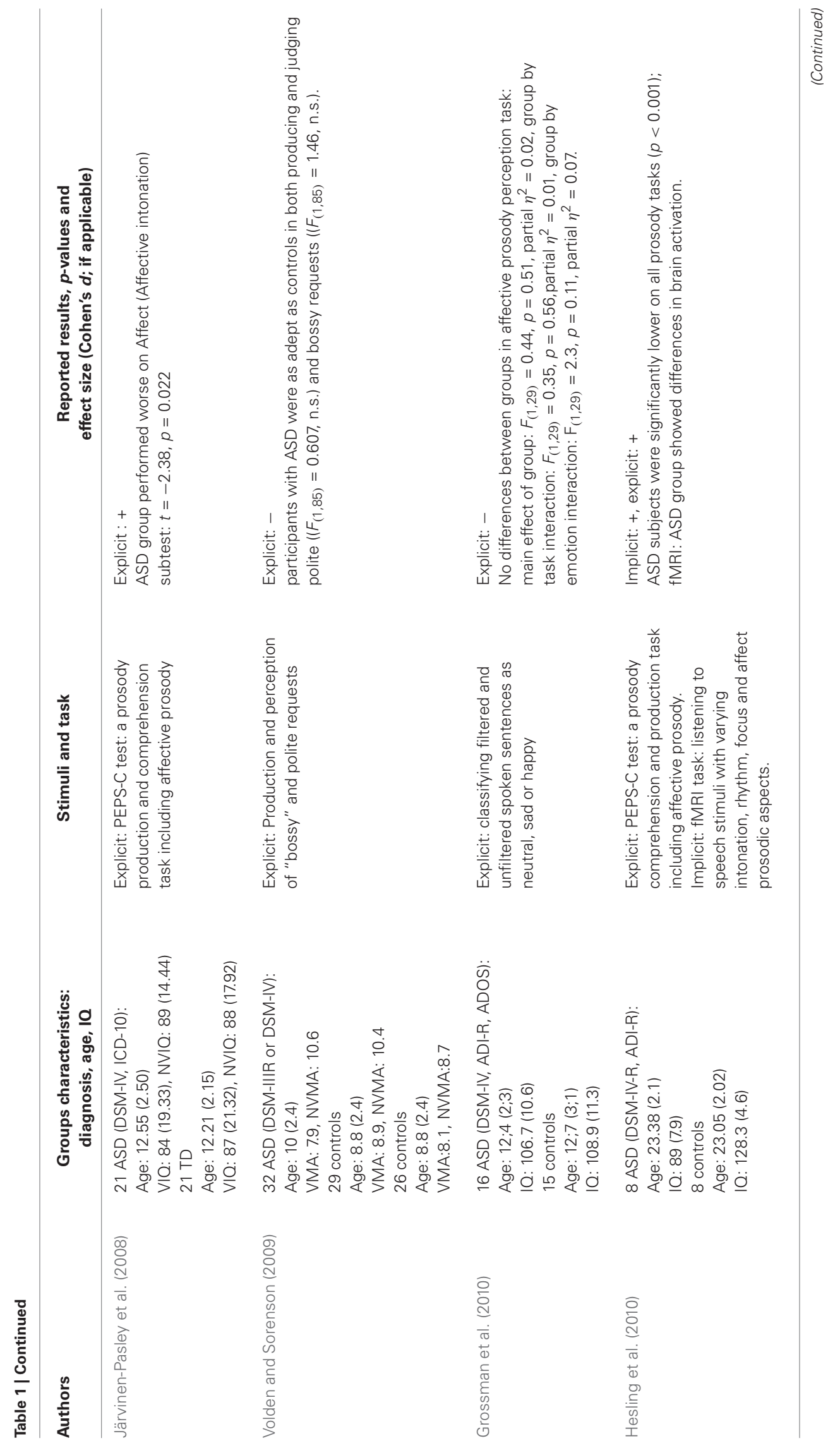




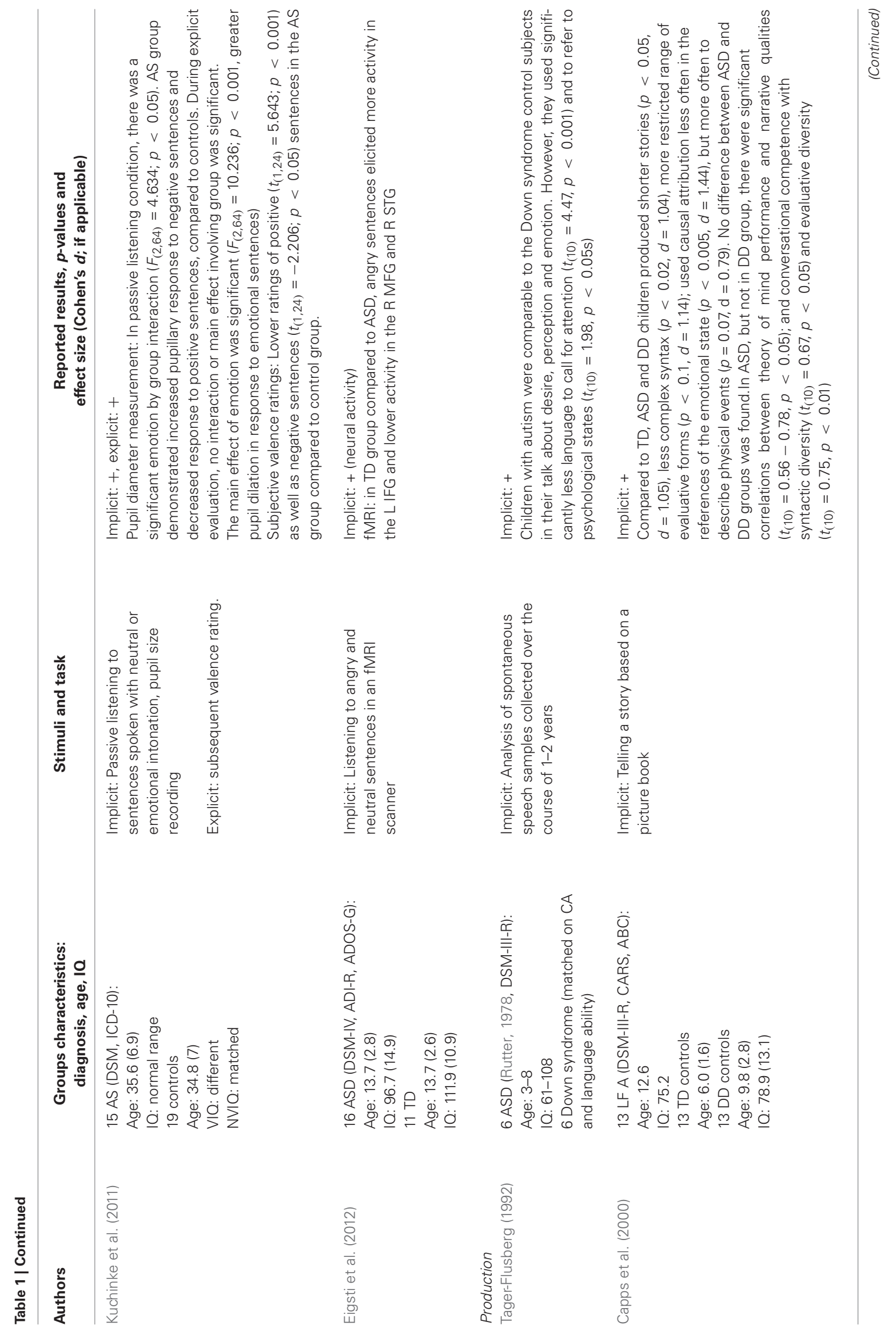




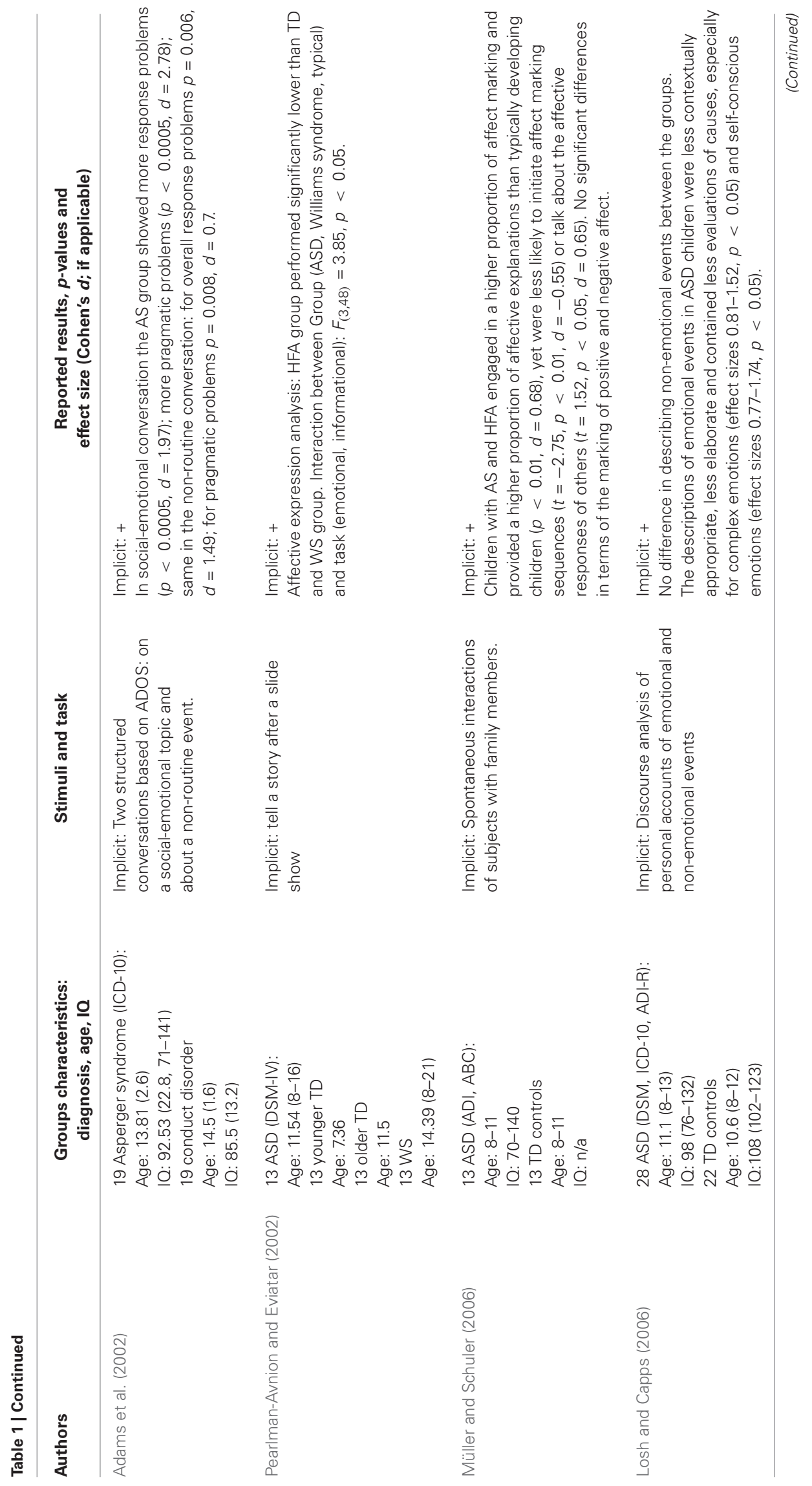




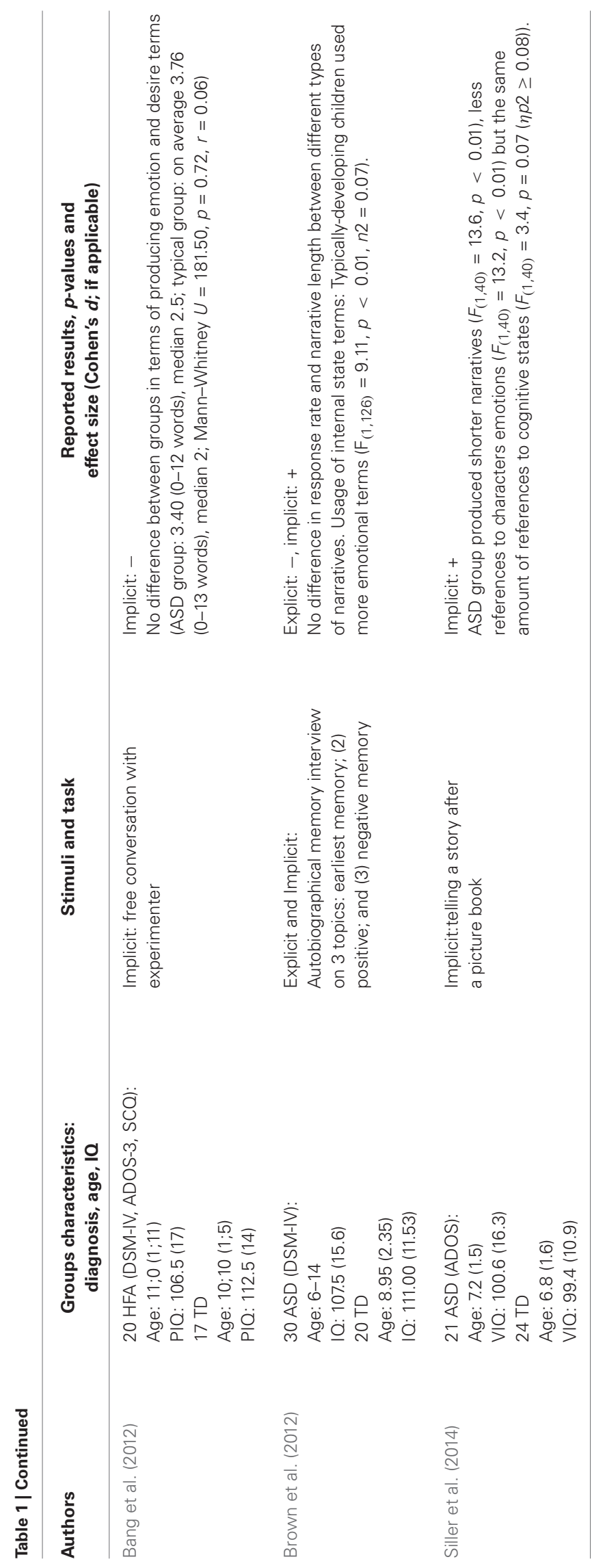


between people. Adults with ASD were less likely than controls to include the characters' emotional state in the description or explanation of their behavior (Barnes et al., 2009). Overall these findings show that individuals with ASD have problems with processing and handling emotional language in memory paradigms, automatic information processing, and in discourse and reasoning.

\section{COMPREHENSION VS. PRODUCTION TASKS}

There is debate on whether or not subjects with ASD have abnormal profiles of production and comprehension of language. Some studies find better production than comprehension in children with ASD for language in general (Hudry et al., 2010b; Miniscalco et al., 2012) while other studies report a more uniform profile of language development (Jarrold et al., 1997). Three of the studies reviewed here used the PEPS-C prosody test which consists of perception and production subtests, including affective prosody; all of these studies showed deficits in both perception and production subtests (Peppé et al., 2007; JärvinenPasley et al., 2008; Hesling et al., 2010). In spontaneous dialog or interview, participants from the ASD group were less likely to mention emotions, describe emotional states (Tager-Flusberg, 1992; Adams et al., 2002; Müller and Schuler, 2006), or use emotional state for a causal explanation of characters' actions (Capps et al., 2000; Pearlman-Avnion and Eviatar, 2002; Brown et al., 2012). In some studies, this neglect was specific to emotions and not present when talking about other types of events (Losh and Capps, 2006); however, one study found no group differences between ASD and typically developing children (Bang et al., 2012).

In all, the data suggest that emotion language impairments are present in both production and comprehension modes. There is no evidence for an imbalance between production and comprehension emotion language skills in ASD.

\section{MODALITY: VISUAL VS. AUDITORY}

Auditorily presented speech unfolds over time, so participants need to continuously pay attention; it is also not possible to go back and listen to parts of it again if something was missed or misheard. Analysis of auditory stimuli also starts earlier, with semantic analysis being made on the basis of partial information before the presentation of the word ends, which results in an earlier onset of semantic ERP effects (Holcomb and Neville, 1990). Previous studies have reported that auditory stimuli compared to visual also elicit stronger behavioral effects: larger and more robust effects of semantic priming and semantic expectancy on reaction times and accuracy (Holcomb and Neville, 1990; Holcomb et al., 1992), as well as greater amplitude and earlier onset of electrophysiological brain responses (Holcomb et al., 1992; Niznikiewicz et al., 1997). This means that visual tasks can be potentially less sensitive and require larger samples to have sufficient power to detect a difference between ASD and control groups. Processing of auditory stimuli compared to visual is also affected by timing of word presentation to a much greater degree (Anderson and Holcomb, 1995), and follows a different developmental trajectory (Holcomb et al., 1992).
From the studies that investigated perception of emotional language, 8 studies presented the stimuli visually (Kennedy et al., 2006; Corden et al., 2008; Gaigg and Bowler, 2008; Mason et al., 2008; South et al., 2008; Gaigg and Bowler, 2009a,b; Han et al., 2014) and 11 studies auditorily (Beversdorf et al., 1998; Boucher et al., 2000; Lindner and Rosén, 2006; Korpilahti et al., 2007; Peppé et al., 2007; Järvinen-Pasley et al., 2008; Volden and Sorenson, 2009; Grossman et al., 2010; Hesling et al., 2010; Kuchinke et al., 2011; Eigsti et al., 2012). In the 11 studies that used auditory modality, 8 studies used explicit measures (participants were asked to identify the expressed emotion), and only one study investigated implicit behavioral measures (memory performance, Beversdorf et al., 1998). In contrast, 7 out of 8 studies using visually presented stimuli looked at implicit measures: reaction time, stimulus detection rate, memory performance, while only three used explicit measures: rating emotional arousal of words on a scale (Corden et al., 2008; Gaigg and Bowler, 2008) or detecting emotionally negative words among neutral (Han et al., 2014). The fact that visual and auditory stimuli were used in different paradigms makes it difficult to assess whether the modality in which the stimulus is presented makes a difference. Explicit measures in studies with auditorily presented stimuli were more likely to show a group difference compared to studies with visual stimuli, suggesting that the transient nature of the auditory signal may indeed make the task more difficult for the ASD group. However, because of the small number of studies we can't draw a definite conclusion. Future studies could address this issue by using visual and auditory language stimuli in the same participants and the same task.

\section{COMPLEXITY OF INFORMATION: WORDS VS. SENTENCES}

Understanding single words for people with ASD is less problematic than understanding complete sentences and natural speech (Tager-Flusberg et al., 2005; Williams et al., 2008).

As indicated in the previous section, many studies on the processing of emotion language have focused on discourse, such as talking about emotional topics and making inferences about emotional states (Adams et al., 2002; Losh and Capps, 2006; Barnes et al., 2009). An alternative explanation could be that the individuals with autism have difficulties expressing complex thoughts in general and that problems in reasoning on emotional topics are not very emotion specific. Therefore, it is important to note that several studies also found impaired performance in the ASD group on tasks that involved detecting or remembering single emotional words. The ASD group performed significantly worse than non-ASD subjects specifically on memory for emotional words (Kennedy et al., 2006; Gaigg and Bowler, 2008, 2009b), although the overall memory performance was similar for ASD and non-ASD subjects. Participants with ASD had less understanding of emotion-related words, but this was not the case for abstract non-emotional words (Hobson and Lee, 1989). In another study where participants had to memorize sentences, participants with ASD showed impaired performance on emotional sentences, but were just as good as controls in remembering neutral sentences with social and Theory of Mind content (Beversdorf et al., 1998). Thus, it was not the case that 
emotional sentences were more difficult for subjects with ASD because of their relation to social context with which ASD participants would be less familiar. In all, it is unlikely that the deficient performance in processing emotional verbal stimuli in the studies reviewed above is due to a general effect of stimulus complexity.

\section{EXPLICIT VS. IMPLICIT MEASURES}

Some studies used explicit emotion measures to investigate emotion processing in ASD: in those studies participants were asked to assign the stimuli to a particular category (happy or sad) or to rate it as positive or negative, or as more or less emotionally arousing. Other studies applied indirect measures of emotional processing, such as the effect of emotion on attention or memory, physiological responses, brain activity, and spontaneous talk about emotion.

Indirect and implicit measures are problematic, because the absence of an emotion effect could be due to a deficit outside the emotional domain, for example, in attention or motivation. Thus, the absence of an emotion effect in the ASD group should be interpreted with caution. On the other hand, explicit measures can also be problematic, especially in subjects with high IQ. Even though these individuals may have impairments in emotion processing, they can use their analytic abilities to design alternative strategies to label stimuli as positive or negative. For example, emotional intonation differs from neutral on a number of acoustic characteristics such as pitch height and variation (Bänziger and Scherer, 2005). If individuals with ASD would focus on isolated features in a prosody perception task, they would be able to correctly classify stimuli as emotional or neutral, but the way they process the stimuli still may be fundamentally different from typical controls, who use a more holistic strategy. Similarly, in facial emotion recognition studies, distinguishing between positive and negative emotion can be done based on single feature, such as upturned or downturned mouth corners, which fits with some of the studies finding atypical gaze patterns in ASD (Neumann et al., 2006). Thus, rather normal explicit responses in the ASD group can only be interpreted in combination with other measures.

Approximately half of the studies using explicit measures report differences between ASD and controls. It is important to consider the difficulty of the applied task. For instance, when participants were asked to classify the auditorily presented sentences as sad and happy, both groups performed in a similar way (Grossman et al., 2010). In more difficult tasks, on the other hand, participants with ASD made more errors than controls: for example, when they had to choose between four response options in a task that required identifying emotion in intonation, (Lindner and Rosén, 2006), or when they had to identify complex emotions of social nature such as embarrassment or jealousy (Hillier and Allinson, 2002; Bauminger, 2004; Rieffe et al., 2007). However, some studies also found lower performance in the ASD group in a simple 2-alternative choice task between sad and happy intonation (Peppé et al., 2007; Hesling et al., 2010), suggesting that the task difficulty should be considered in combination with age and functioning level of the participants. To conclude, in certain circumstances participants with ASD have trouble with fine differentiation between various emotions and perform worse than control subjects. Unfortunately, all of the studies either provided participants with response options, or asked to rate them on one single scale. Potentially, naming the emotion in a free response task, or rating the stimuli on several scales at once (for example, valence and arousal) and having to distinguish between these different aspects, would be more challenging, and this kind of task should be more likely to uncover group differences.

Studies that use implicit measures report strongly variable findings. Behavioral results are very much dependent on the task used, and with respect to some tasks, the results are still preliminary. For example, only 2 studies so far report attenuated attention blink effect (Corden et al., 2008; Gaigg and Bowler, 2009a), and 4 studies find a weaker effect of emotion on memory in ASD compared to non-ASD subjects (Beversdorf et al., 1998; Kennedy et al., 2006; Gaigg and Bowler, 2008, 2009b) but another study does not (South et al., 2008).

With respect to activity of the autonomic nervous system, the studies measuring skin conductance response (SCR) modulation found typical responses during reading emotion words compared to neutral ones in the ASD group (Corden et al., 2008; Gaigg and Bowler, 2008). These studies used highly arousing emotional words, such as profanities, taboo words and sexually explicit words, and the highly arousing nature of these stimuli could be the reason why they elicited an autonomic response not only in typical but also in ASD group. Another study measuring pupillary response to the stimuli with an intermediate level of emotional arousal (sentences spoken with positive and negative intonation) showed increased response to negative stimuli and decreased response to positive (Kuchinke et al., 2011). This is in agreement with yet other studies showing absent or reversed responses of the autonomous nervous system in an anxiety-provoking situation in people with ASD (Kushki et al., 2013). Due to the small number of studies and differences in autonomic measures and design, it is not yet possible to reach a conclusion with respect to physiological correlates of emotions in ASD, but the preliminary evidence suggests that participants with ASD may be less sensitive to subtle variations in emotional valence, while stimuli with high emotional arousal are equally likely to elicit an autonomic response in ASD and typical population. More research in this field is needed.

Moving now to the studies of brain activity, our selection included 5 fMRI studies and one EEG study (Korpilahti et al., 2007). All of them report significant between-group differences with respect to processing of emotion language at the neural level. Studies report less deactivation of the default-mode network regions for visual or auditory emotional stimuli compared to neutral stimuli or rest in the ASD group (Kennedy et al., 2006; Hesling et al., 2010), suggesting that individuals with ASD may have trouble suppressing task-irrelevant regions and focusing on the relevant stimuli characteristics. The medial prefrontal cortex (MPFC) was more active during rest than during task performance in the typical group, and during task it was more active in response to emotional compared to neutral words (Kennedy et al., 2006). However, the ASD group failed to show any modulation of activity in this region in either of the comparisons. Medial prefrontal regions have been previously implicated in evaluation of stimuli as pleasant or unpleasant (Maddock et al., 2003) and in 
silent generation of emotionally positive or negative words (Cato et al., 2004). A lack of modulation of activity in this area in the ASD group suggests an impairment in the processes of evaluation, but it also indicates that people with ASD may engage in different kinds of cognitive processing during resting state, as indicated by higher activity in MPFC at rest in typical group compared to ASD group. Participants with ASD also showed greater activation in the left supramarginal gyrus (implicated in phonological processing) during an auditory task (Hesling et al., 2010), suggesting that the ASD group focused more on phonological rather than conceptual features of the input. Furthermore, studies with verbal stimuli find more activity outside of the language network in the ASD group: fusiform gyrus (Han et al., 2014), right hemisphere homologs (Mason et al., 2008; Eigsti et al., 2012), and brain areas typically involved in memory and control, such as parahippocampal gyrus and globus pallidus (Eigsti et al., 2012). These results suggest that individuals with ASD recruit a different network of brain areas during emotional language tasks, which results in less efficient processing and requires additional involvement of the homologous regions from the right hemisphere. The EEG study comparing electrophysiological responses to auditorily presented neutral and angry sentences found increased mismatch negativity (MMN) amplitude in the ASD group compared to the control group, suggesting that participants with ASD focused more on the low-level acoustic characteristics of the utterances, in contrast to typical group which was processing the stimuli in a more global way. Additionally, there were differences between group in terms of lateralization of the components. Typical children showed larger N1 amplitudes over the right hemisphere and larger late MMN amplitudes over the left hemisphere, but the ASD group showed less lateralization for MMN and N1, with greatest differences between groups over the right hemisphere (Korpilahti et al., 2007). However, this study did not have a behavioral measure, thus it is difficult to make direct inferences from differences in electrophysiological responses to the corresponding cognitive processes.

In sum, the studies reviewed here demonstrate that subjects with ASD have widespread impairments in processing emotional language, and these impairments are present in tasks tapping into different cognitive domains, in comprehension as well as production tasks, and tasks of varying levels of complexity. These impairments are also reflected in abnormal concomitant physiological and neural responses.

\section{SUMMARY}

To summarize, individuals with ASD are able to correctly identify words, sentences or stories as emotionally positive or negative (Volden and Sorenson, 2009; Grossman et al., 2010; Brown et al., 2012), but have difficulty with providing an in-depth explanation (Bauminger, 2004; Rieffe et al., 2007). Implicit behavioral measures show more robust and consistent between-group differences (compared to studies that use explicit behavioral measures). The overall tendency is that subjects with ASD have a poorer memory for emotional events (Gaigg and Bowler, 2008, 2009b), are less inclined to direct attentional resources to emotional stimuli (Korpilahti et al., 2007; Corden et al., 2008; Gaigg and Bowler, 2009a) and mention emotions in spontaneous conversations
(Capps et al., 2000; Barnes et al., 2009) than typically developing participants. Studies of autonomic activity are very few in number and show mixed results. In contrast, neuroimaging studies report consistently diminished brain activation in response to emotional stimuli in subjects with ASD compared to typical participants. At least in studies using auditory stimuli, the brain activity results suggest that participants with ASD are more likely to focus on phonological features of the input rather than process it in the holistic manner, as we hypothesized in Section Explicit vs. Implicit Measures (Korpilahti et al., 2007; Hesling et al., 2010). However, only a small number of studies investigated brain activity (1 study with EEG and 5 studies with $\mathrm{fMRI}$ ), therefore more studies are required before we can draw more firm conclusions.

It was shown that high-functioning subjects with ASD are able to interpret others' emotional behavior correctly and react with an appropriate emotional response if they are provided with explicit cues, in spite of their problems with spontaneous emotional interactions (Begeer et al., 2008). There are two alternative explanations for the discrepancy between absent spontaneously applied and relatively intact cue-related emotional skills and responses in ASD. One option is that individuals with ASD have adequate and typical conceptual representations of emotions, but have trouble applying them in real life. The alternative explanation is that the emotion concepts of ASD individuals are actually different from typical individuals and are more similar to neutral concepts. The evidence from the behavioral studies of attention and memory (Beversdorf et al., 1998; Corden et al., 2008; Gaigg and Bowler, 2008, 2009a,b) points towards the latter alternative, and the few available neuroimaging studies suggest that individuals with ASD largely recruit the same neural networks for processing emotional and neutral language (Kennedy et al., 2006; Hesling et al., 2010). However, this is only a preliminary conclusion that needs to be backed up by more research, particularly on autonomic activity and electrophysiology.

\section{EMOTIONAL LANGUAGE IMPAIRMENT AND GENERAL INTELLIGENCE}

About half to two-third of people with ASD also have some form of intellectual disability (Matson and Shoemaker, 2009). Language impairment in ASD has a more complex pattern. Higher order linguistic functions, such as semantics and pragmatics (understanding contextual and non-literal meaning, inferring speaker intentions) are almost universally impaired in ASD, while phonology, lexicon and syntax are affected to varying degrees in different subgroups (Groen et al., 2008; Eigsti et al., 2011). Some researchers also report more deficits in language comprehension than in production (Hudry et al., 2010a). In the following part we will discuss the link between impairment in emotional language processing and (1) history of language delay; (2) presence of intellectual disability; and (3) individual differences in verbal and nonverbal IQ within normal range.

\section{ARE IMPAIRMENTS IN EMOTIONAL LANGUAGE RELATED TO LANGUAGE DELAY?}

By the definition of the DSM-IV criteria, subjects with Asperger have normal milestones for language acquisition in the first years after birth (APA, 2000). If emotional impairments in ASD are 
in part due to a delay in language acquisition, we would expect that studies including subjects with Asperger syndrome would more often report negative results, in other words find less of even no differences between the control and patient group on emotional language measures. However, this appears not to be the case. Individuals with Asperger syndrome have serious problems in talking about social-emotional topics (Adams et al., 2002). Furthermore, they have an abnormal Event-Related Potentials (ERP) pattern when hearing angry intonation (Korpilahti et al., 2007), fail to show modulation of attention blink effect by emotional content of the words (Corden et al., 2008), and show a different pattern of pupillary response when hearing emotional sentences (Kuchinke et al., 2011). In all these aspects of emotion processing, subjects with Asperger syndrome differ from controls, despite their rather intact early language skills and absence of language delay. Therefore, their impairment in emotional language cannot be explained by developmental delay in language and communication. However, none of the studies compared a group of participants with Asperger syndrome to a group with autism and language delay within the same paradigm. Therefore, the question remains whether individuals with classic autism who frequently have early language delays, would demonstrate a greater degree of emotion language impairment under the same task conditions.

If the overall level of language development is a decisive factor for the normal development of emotional competence and processing of emotional stimuli, emotional language impairments should also diminish or even disappear when people with ASD catch up in their language development with their peers. However, this does not appear to be the case, since the emotional impairments do not disappear when the participants become older and acquire better language skills. The participants in the studies ranged from 3-year-old children to adolescents and adults, and differences in emotional language processing occurred in subjects with ASD in all age groups. Furthermore, although highfunctioning individuals with ASD, and thus without language delay, from various age groups were able to provide adequate explicit evaluations of emotional stimuli, they showed atypical performance compared to control subjects on measures of memory performance, attention, and autonomic activity in relation to the processing of emotional language stimuli. The cause of the absence of behavioral differences in some tasks remains an open question, but one likely explanation is that high-functioning ASD subjects develop compensatory strategies by explicitly learning the relation between a situation and an emotional label (Begeer et al., 2008; see also Hobson, 1991).

Comparison of the results to a non-emotional task of similar difficulty can also help to address the issue of whether or not emotional language difficulties in ASD are a consequence of more general language delay. Several studies have used such control tasks. They found that the atypical performance in the ASD participants was relatively specific to emotional stimuli, and did not extend to other semantic features of the verbal materials: namely semantic relatedness (Gaigg and Bowler, 2008), distinctiveness of individual words (Corden et al., 2008; Gaigg and Bowler, 2009a), or the conceptual content of sentences (Beversdorf et al., 1998).

\section{ARE IMPAIRMENTS IN EMOTIONAL LANGUAGE RELATED TO THE PRESENCE OF INTELLECTUAL DISABILITY?}

The next question is whether the emotional impairments are related to the presence of general intellectual disability. If so, emotional impairments should show a different degree of severity in individuals with ASD with high and low IQ. One possibility is that individuals with ASD and intellectual disability would show a greater degree of emotional impairment. Most of the studies we identified tested individuals with normal or above normal intelligence, and only 8 studies included a sample of low-functioning subjects (Hobson and Lee, 1989; Boucher et al., 2000; Capps et al., 2000; Hillier and Allinson, 2002; Pearlman-Avnion and Eviatar, 2002; Williams and Happé, 2010). It is difficult and even problematic to estimate whether and how emotional language stimuli are processed in low-functioning subjects with ASD, because more complex tasks can't be administered in this population. Further, the problems specific to emotional information add up with problems in understanding the instruction and performing the task in general. Thus, in more difficult tasks specific difficulties with emotion processing may be obscured, for instance, by the effects of shorter attention span, poor understanding of the task, tendency for impulsivity, or response perseveration. Simpler tasks, on the other hand, may lead to ceiling effects in both groups.

Notwithstanding these methodological problems, some studies reported that low-functioning individuals with ASD performed worse on emotion language task than mental agematched healthy controls (Rieffe et al., 2007). In contrast, other studies found that low functioning ASD subjects performed equally (Capps et al., 2000; Williams and Happé, 2010) or even better (Boucher et al., 2000) than children with a linguistic or intellectual impairment. These discrepant findings could reflect differences in emotional skills between the groups, but could also be due to the task demands being too high, particularly for the children with an intellectual disability. This confound makes it difficult to determine whether the emotional language impairment is due to a specific emotional deficit or to suboptimal general cognitive skills.

Additionally, it is also possible that individuals with ASD with extremely high IQ would also show greater degree of emotional impairment compared to people with average IQ. Other domains, such as restricted and repetitive behaviors, were previously shown to have such complex association with IQ (Bishop et al., 2006). None of the studies included in our review specifically looked at a subgroup of people with ASD with extremely high IQ, although the reported variance of IQ scores suggests that at least a few of their participants had IQ scores in the extremely high range.

So far, the issue of whether emotional language impairments are present to a similar degree in individuals with ASD with varying levels of IQ has not been fully explored. A possible design is to include three groups of subjects with ASD (functioning in the low, middle and superior range of intelligence) and three age and IQ matched non-ASD control groups, and examine whether any discrepancies on emotional language tasks between ASD and matched controls would vary systematically as a function of IQ. 


\section{ARE IMPAIRMENTS IN EMOTIONAL LANGUAGE RELATED TO VARIATION IN GENERAL INTELLIGENCE?}

Another way to explore the dependance of emotional impairments on IQ differences is to directly calculate the within-group correlation between the performance in the experiment and IQ. If the variation in IQ would matter and would be causally linked to the task performance, we would expect the verbal or nonverbal IQ to negatively correlate with the degree of emotional language impairment within the ASD group. This was examined in seven studies. Three studies found a positive correlation between performance on emotional task and verbal IQ (Gaigg and Bowler, 2009a; Williams and Happé, 2010; Siller et al., 2014), and in three studies the correlation was not significant (Hillier and Allinson, 2002; Lindner and Rosén, 2006; Losh and Capps, 2006). Two studies reported correlations with nonverbal abilities; one study found a significant positive correlation (Hillier and Allinson, 2002), while the other study reported a nonsignificant relationship (Losh and Capps, 2006). Finally, two studies did not look separately at verbal and nonverbal components: one study found a significant positive relationship with mental age (Bauminger, 2004), while the other study found no association with IQ (Han et al., 2014). Because of the small number of studies, it is hard to reach a definite conclusion on whether IQ plays a significant role in performance. However, the fact that only half of the studies found an effect of IQ while the other half found no effect suggests that even if the effect is there, it must be rather weak. Finally, in case of the studies that do not report any data on association between IQ and their measures of interest, it is not clear whether those studies did not investigate the effect of IQ, or whether they found a statistically nonsignificant effect and decided not to report it. A general recommendation for future studies would be to report the relationship between IQ and the outcome of interest, even if this relationship is not statistically significant.

In summary, from these data we can conclude that language delay, presence of intellectual disability or variation in general intelligence cannot fully explain impairments in the processing of emotional language in subjects with ASD. In fact, there is more evidence for impairments of emotion language in highfunctioning subjects with ASD and in subjects with Asperger, when compared to appropriate matched control subjects, than in low-functioning subjects with ASD. Nonetheless, variation in general intelligence still plays a role to some degree, although not in all types of tasks, and not with all types of stimuli. The extent to which IQ differences influence emotional language processing remains an open issue that merits further study.

\section{CONSEQUENCES OF EMOTIONAL LANGUAGE IMPAIRMENTS FOR OUR UNDERSTANDING OF ASD}

So far we have concluded that emotional language impairments in ASD are widespread and not restricted to any particular cognitive domain or stimulus type; they are even more pronounced in subjects with high-functioning autism and Asperger syndrome than in individuals with intellectual disability, language problems or language delay; and they persist through all age groups. These emotional language impairments complement the emotional impairments for the recognition, processing, understanding and production of facial and visual displays of emotions, which have been reviewed extensively by others (Jemel et al., 2006; Harms et al., 2010). In this next section, we will discuss whether and how these widespread and rather general emotional impairments can be accounted for by existing cognitive theories of autism.

\section{EMOTIONS AND GLOBAL VS. LOCAL PROCESSING}

The central coherence account proposes that autism is characterized by a particular cognitive style of information processing, which can be described as detail-oriented, with particular attention paid to separate parts or aspects of an object (Happé, 2005; Happé and Frith, 2006). In contrast, typical individuals have a strong preference for global processing and integration, also known as central coherence. The evidence supporting the deficit in central coherence in ASD comes from a wide range of studies, including different kinds of visual and semantic tasks (Happé, 2005). However, this theory was developed primarily to explain the pattern of cognitive strengths and weaknesses in autism, and it was not intended to explain the emotional and social-communicative impairments of subjects with ASD.

Weak central coherence seems to explain only part of the evidence with regard to emotional impairments reviewed above. The emotional meaning of an image, a musical piece, or a text may not be evident from the details and only apparent when the stimulus is processed as a whole and/or put into context. If individuals with ASD indeed would miss the emotional meaning of a stimulus because of weak central coherence skills, this would be evident in their explicit evaluation of the stimuli. However, this is not the case; in fact, several studies demonstrated that subjects with ASD could correctly classify spoken sentences as emotionally positive or negative (Volden and Sorenson, 2009; Grossman et al., 2010; Kuchinke et al., 2011), and also provided similar rating of emotional arousal of emotion words as the control group (Corden et al., 2008; Gaigg and Bowler, 2008). Additionally, according to the central coherence account, more complex stimuli (text, stories) would be problematic to subjects with ASD while more simple stimuli such as single words would not be. However, a number of studies found group differences when using single words (Corden et al., 2008; Gaigg and Bowler, 2008, 2009a,b). Finally, if individuals with ASD would be unable to quickly grasp the emotional meaning of a stimulus, we would expect that the neural or autonomic responses to emotional stimuli would not differ from neutral stimuli. However, several studies found that startle potentiation in ASD subjects differs not between positive and negative stimuli, but between these and neutral stimuli, which means that the emotional stimuli do have an effect, but are processed in an atypical way (Wilbarger et al., 2009; Dichter et al., 2010).

There have also been attempts to integrate socialcommunicative impairments into the central coherence account, by arguing that integrative and holistic processing is essential for social cognition and Theory of Mind skills (Happé, 1997; Jarrold et al., 2000). However, some studies reported that individuals with ASD who pass the Theory of Mind task and those who fail have a similar lack of central coherence performance. This supports the notion that central coherence and theory of mind deficits are independent (Happé, 1997, 2000). Additionally, it is still debated 
whether central coherence in ASD is weak or deficient, or just unused, because under some task conditions subjects with ASD are able to display holistic processing (Happé and Frith, 2006).

An alternative to the Weak Central Coherence account is the Enhanced Perceptual Functioning (EPF) model (Mottron and Burack, 2001; Mottron et al., 2006). This model proposes that individuals with ASD are not impaired at global processing, but they are better at processing details. As a consequence, spontaneously they choose a more detail-oriented processing style, even though they are able to focus on the global picture when they are explicitly instructed to do so. According to the EPF model, focusing on the perceptual aspects and ignoring the conceptual aspects of the stimuli could lead to a relative lack of processing emotional information. This would explain why participants with ASD would utilize emotional information in some tasks but not in others (Gaigg and Bowler, 2008; South et al., 2008). Future studies need to address this issue, for example, by considering whether a focus on different levels of processing (e.g., superficial perceptual feature analysis or deep semantic analysis) may explain the difference in processing emotion by ASD and typical groups.

\section{EMOTIONS AND EXECUTIVE DYSFUNCTION}

Another influential theory proposes that the executive dysfunction is at the core of ASD (Ozonoff et al., 2005). Executive function is a broad term that refers to a group of cognitive functions that include monitoring of one's own behavior, cognitive control, flexibility, inhibition, planning and working memory (Eslinger, 1996). Deficits in various aspects of executive function are observed not only in ASD, but also in many other psychiatric disorders, such as ADHD (Willcutt et al., 2005). Problems in executive function in ASD are especially evident for cognitive flexibility, with inhibitory control and working memory being less affected (Ozonoff et al., 2005).

Research has suggested a link between executive functioning and the processing of emotions (Pessoa, 2009). Research in other clinical populations found that executive control measures correlate with performance in tasks tapping into emotional and motivational systems in schizophrenia (Lee et al., 2009), measures of cognitive control correlate with mood in patients with traumatic brain injury (McDonald et al., 2010), and cognitive flexibility and response inhibition correlate with empathy measures in depressed patients (Thoma et al., 2011). However, emotions and executive functions are thought to be rather separate systems that rely on different brain networks (Seeley et al., 2007). Furthermore, while mood state and emotional significance of the stimuli can certainly have an effect on executive function (Pessoa, 2009; Mueller, 2011), there is no evidence that executive functioning by itself has major effects on emotion processing, in particular on fast stimulus-driven responses (Corden et al., 2008; Gaigg and Bowler, 2009a) and autonomic activity (Kuchinke et al., 2011). Therefore, deficits in executive functioning are not a sufficient explanation for the emotional impairments in ASD.

\section{EMOTIONS AND THEORY OF MIND}

The development of emotion understanding is tightly linked to the development of social relationships and the accumulation of experience in interaction with others. One of the influential cognitive models of ASD is the Theory of Mind account. It assumes that people normally develop an ability to attribute mental states to themselves and to other people (Leudar et al., 2004; Sodian and Kristen, 2010). This ability is also called Theory of Mind reasoning or mentalizing. Mentalizing is required to reason about thoughts and desires of people, infer their feelings and beliefs, and predict their actions. People with ASD have problems in attributing mental states to themselves or to other people (Yirmiya et al., 1992; Lombardo et al., 2007; Jones et al., 2010; Schulte-Rüther et al., 2011). Reasoning about other people's emotions is also a part of Theory of Mind abilities. Therefore, problems in deriving emotional meaning from text, describing one's emotional state, and explaining why one should feel sad or happy might rely on general Theory of Mind ability.

However, differences in emotional awareness in subjects with ASD were found to be independent from impairments in selfreflecting and mentalizing skills (Buitelaar et al., 1999; Silani et al., 2008). Furthermore, while emotions play an important role in social interactions, they are not limited to social phenomena and fulfill important additional psychological functions. For example, emotions play a role in detecting potentially important threatening or pleasant stimuli and triggering an appropriate approach or avoidance behavioral response. Some of the studies dealing with fast automatic responses to motivationally relevant stimuli (angry voice, scary, or pleasant pictures) tapped into this aspect of emotions (Dichter et al., 2010; Kuchinke et al., 2011). Those responses are very fast and bottom-up in nature, and involve a person's own affective reaction rather than an explicit reflection on his or her own mental state. Those abnormal automatic emotional reactions thus cannot be readily and completely explained by a Theory of Mind deficit.

\section{EMOTIONS AND ALEXITHYMIA}

Recent studies suggest a link between ASD and alexithymia (Silani et al., 2008; Bird et al., 2011). Alexithymia is defined as a difficulty in identifying and describing one's own feelings and difficulty in distinguishing one's feelings from bodily sensations of emotional arousal (Nemiah, 1977). Alexithymia is thought to characterize about $10 \%$ of the general population (Linden et al., 1995; Salminen et al., 1999). Although alexithymia is neither a necessary nor a sufficient feature of ASD, it is present in approximately $50 \%$ of individuals with ASD (Hill et al., 2004; Berthoz and Hill, 2005; Lombardo et al., 2007). Alexithymia is typically assessed based on self-report questionnaires such as TAS-20 (Bagby et al., 1994). The key question here is whether the emotional deficits of subjects with ASD described above are linked to alexithymia (Silani et al., 2008; Bird et al., 2010).

There is evidence that the empathy deficits reported in ASD are indeed related to alexithymia. Subjects with ASD who were not alexithymic demonstrated normal empathic responses, but individuals with ASD and alexithymia showed clear empathy deficits (Bird et al., 2011). The alexithymia account fits with the problems in understanding emotions in text, images, and music. Some studies report that subjects with ASD were able to adequately rate the stimuli on their 
emotional valence (Corden et al., 2008), which at first glance seems to be contradicting the findings from alexithymia studies. However, the scale used in these studies was rather simple and asked only for a differentiation of positive and negative valence.

Introspection into one's own inner state is a rather complex skill that only develops in childhood (Flavell et al., 2000), but the first symptoms of autism are often apparent before that. Therefore, it is likely that instead of being a cause, both alexithymia and a lack of empathy in ASD arise as a consequence of impaired emotional processing. For example, some studies report that automatic reflexive responses in ASD do not differentiate between positive and negative valence (Wilbarger et al., 2009; Dichter et al., 2010). These low-level processing abnormalities may give rise to a general problem with identifying and categorizing emotional states in other persons and in oneself. Further studies are needed to examine whether alexithymia is a useful construct to subtype subjects with ASD and to examine the underlying physiological and neural mechanisms of impaired emotion processing and empathy deficits.

\section{EMOTIONS AND MOTIVATION: REWARD AND PUNISHMENT LEARNING}

As described earlier, emotions are linked to evaluation of the motivational significance of an object or event and to the motivational system in general (Frijda, 2010; Mesquita and Frijda, 2011). Altered sensitivity to reward would lead to a difficulty in estimating the motivational saliency of the stimuli and hence their emotional meaning. Studies of motivation and processing of reward and punishment in ASD are scarce; however, available data suggest deficits in the processing of reward (Scott-Van Zeeland et al., 2010; Kohls et al., 2011). For example, children with ASD performed abnormally on a delayed non-match to sample task. In this task, a stimulus which is not associated with reward in the current trial will be the one associated with reward in the next trial. Children with ASD had trouble learning stimulus-reward associations and flexibly adjusting them in the course of the task (Dawson et al., 2001). Several neuroimaging studies investigating social (smiling face) and nonsocial (monetary) rewards in subjects with ASD found diminished activations in neural networks associated with processing of reward and punishment: nucleus accumbens (NA; Dichter et al., 2012b; Kohls et al., 2013), ACC (Scott-Van Zeeland et al., 2010; Kohls et al., 2013) and striatum (Scott-Van Zeeland et al., 2010). Additionally, neural response to reward in the left ACC was found to correlate with measures of social interaction abilities in the ASD group (Schmitz et al., 2008).

Another fMRI study used two reward conditions, one consisting of monetary reward, and the other consisting of objects that are typically interesting and relevant for ASD individuals: machines, trains, electronic devices. Control group showed significantly greater activation of the NA in the monetary reward condition, while in the ASD group the NA activity was not significantly different in the two conditions, and not significantly different from the control group in the object reward condition (Dichter et al., 2012a). This result suggests an impairment in the reward processing system in the ASD group, including a diminished anticipation of reward and a lower salience of reward in general. An impairment in reward processing was also found in an ERP study using a different paradigm, where subjects with ASD demonstrated an attenuated P3 component during reward anticipation in response to cues associated with both social and monetary reward (Kohls et al., 2011), suggesting hyporesponsivity to reward in the ASD group and reduced attention allocation to incentive stimuli. However, another EEG study examined a different ERP component (namely, feedback related negativity) and reported no difference between ASD and control groups for positive compared to negative feedback (Larson et al., 2011). This suggests that the dysfunction in the motivational system affects early stages (anticipation of the outcome) to a greater degree compared to later stages (post-feedback processing), and processing of rewards to a greater degree compared to losses.

In all, these data indicate that subjects with ASD are less sensitive to social and nonsocial rewards, as reflected in lower activations of the reward areas of the brain, and even may react with distress to reward given increased activity of the amygdala and insular cortex (Dichter et al., 2012b). The question of whether problems in motivation and sensitivity to reward cause problems in emotions, or, instead, deficient emotional responses lead to problems in motivation, is not fully clear yet. The link between motivational processes and processing of emotional stimuli in ASD needs to be studied further.

\section{EMOTION, SIMULATION, AND THE MIRROR NEURON SYSTEM}

Embodied simulation theory states that people understand other people's actions by directly simulating them (instead of logically inferring their intentions through metacognitive reasoning; Gallese, 2007; Gallese and Sinigaglia, 2011). They do so by activating the same brain networks which would also be activated if the observer would be performing the same action. For example, when one observes other people's actions, a pattern of motor activity is activated that corresponds to the neural pattern of when the observer would perform the same action. According to the simulation theory, this MNS plays an important role in understanding and predicting actions of other people in a rather direct way and without necessarily involving more indirect mentalizing skills. Recently, it has been proposed that our brain simulates not only actions, but also emotions of others (Decety and Jackson, 2004; Keysers and Gazzola, 2006) and in this way facilitates understanding others' inner emotional states (Perry et al., 2010; Sinigaglia and Sparaci, 2010). Observing other people's facial expressions is associated with increased activity in regions of the inferior precentral and inferior frontal gyri that are also involved in producing similar expressions (Carr et al., 2003). This activity is thought to trigger congruent activity in emotional brain regions such as the insula and the amygdala (Carr et al., 2003; Jabbi and Keysers, 2008). Activity in the frontal parts of the MNS was found to be associated with the tendency to empathize with other individuals (Gazzola et al., 2006; Jabbi et al., 2007; Saarela et al., 2007; Pfeifer et al., 2008). On the reverse, lesions of this area were associated with deficits in empathy and emotion recognition (Shamay-Tsoory et al., 2009). 
A "broken MNS" hypothesis could explain both the social and emotional impairments in ASD (Iacoboni and Dapretto, 2006). This hypothesis is supported by data from behavioral studies and a variety of structural and functional abnormalities found in the MNS region (Dapretto et al., 2005; Hadjikhani et al., 2006). However, recent evidence shows that under different task conditions MNS in autism seems to be intact (Hamilton et al., 2007). Overall, the empirical evidence for the broken mirror hypothesis of ASD is rather mixed and includes a number of studies yielding disconfirming evidence (Hamilton et al., 2007).

It is possible that the abnormal functioning of the MNS observed in the early studies is caused by a deficit outside the MNS. Some authors suggested that the MNS is not dysfunctional on its own, but that motivational abnormalities draw the child's attention away from social and towards idiosyncratic stimuli. As a result, the MNS does not receive a proper input and therefore does not develop fully (Esser et al., 2010). In a recent review, it was further suggested that other neural systems besides MNS, such as networks involved in attention and control, may be responsible for the inconsistent findings with regard to imitation in ASD (Kana et al., 2011).

\section{CONCLUSIONS AND PERSPECTIVES}

The results of our systematic review allow us to draw several conclusions. First, the data supports the existence of impairments in the processing of emotional language in individuals with ASD that are relatively independent of the complexity of stimuli (single words, sentences or discourse), task (production or comprehension, recognition, recall or detection), and of the sensory modality (visual or auditory). These impairments were found in different tasks tapping in reasoning, memory, or attention to emotional stimuli. The evidence for atypical physiological or neural responses is limited due to a small number of studies.

Second, these emotional impairments have been documented in ASD participants with average or even above average cognitive abilities and appear to be rather independent of the level of language development. Studies in low-functioning subjects with ASD, however, are less well suited to differentiate specific problems in handling emotional stimuli from more general emotional deficits due to cognitive problems.

Third, the existence of impairments in emotional language processing has implications for our understanding of the relationship between emotional and social deficits in ASD. In contrast to more concrete stimuli such as faces, linguistic representations of emotion are more abstract, and proficient understanding of them is dependent on verbal ability and develops later compared to reading expressions from faces or body postures (McClure, 2000; Adolphs, 2002). Emotional language can be used in a context that does not involve interaction with another persons. A person could know a word for a specific emotion without having a good understanding of this emotion. For example, people with amygdala lesion become impaired in the ability to understand and recognize fear (Broks et al., 1998), but they do not forget the word "fear" itself. Conversely, it's also possible to understand another person's inner state without having a verbal label to describe this state. It seems reasonable to hypothesize that a common emotional impairment may underlie the impairments in both facial emotion processing and in emotional language.

Fourth, we explored how well cognitive accounts of ASD may explain the emotional impairments in ASD. Classic cognitive theories of ASD, namely Theory of Mind, Executive Dysfunction and Weak Central Coherence, have limited power to explain emotional impairments in ASD. On the other hand, findings from studies on reward and punishment learning offer a more promising account of the emotional impairments. More work in this area is warranted. Finally, alexithymia appears to be a useful construct to subtype subjects with ASD, to examine its underlying physiological and neural mechanisms and to link it to broader aspects of emotional functioning in social interaction.

On a broader level, this review indicates that emotional impairments in ASD should receive more attention from both researchers and clinicians. Emotional impairments in ASD were brought forward by Kanner already in his seminal description in 1943, but since then have shifted to the background. In the current classification systems DSM-5 and ICD-10, emotional symptoms are regarded as part of, or as secondary to, problems in social interaction and communication. Bringing emotional symptoms in ASD to the attention of researchers may inform our understanding of ASD in several ways. We can then establish whether emotional impairments are present across the whole autism spectrum, are specific for ASD, or resemble the deficits observed in other disorders such as schizophrenia or anxiety disorders. Further, this will allow us to provide a more detailed and accurate description of the clinical manifestations of ASD. This would facilitate identification of more homogeneous subgroups and stimulate the study of emotional competence of subjects with ASD within and outside the social context and across various levels of structure of social contexts. Finally, this would increase investments in developing and testing therapeutic interventions for emotional deficits in ASD.

Emotional and social development are tightly linked to each other. Many emotions, such as shame or embarrassment, are social in nature, and displays of emotion are important elements of everyday social interactions. Trouble understanding the emotions of other people can lead to great difficulties in social functioning. The emotional aspects of social interaction received considerable attention from researchers (Begeer et al., 2008). However, 'emotional' and 'social' are not the same. Emotions do not only have social, but also psychological and biological components, are tightly related to the system of motivations and needs (Frijda, 2008; Larsen et al., 2008; Mesquita and Frijda, 2011), and are responses to unconditional stimuli such as pain. In turn, social interaction cannot be reduced to purely emotional aspects. Various models of social interaction include cognitive components, such as overt encoding and interpretation of behavioral cues and selecting an appropriate response (Crick and Dodge, 1994, 1996), and implicit cognition such as implicit judgment biases and memory (Greenwald and Banaji, 1995; Amodio and Ratner, 2011). Some authors suggest that simulation is a crucial component of social cognition (Barsalou, 2008), and that the MNS is the neural mechanism of simulation (Wolpert 
et al., 2003; Uddin et al., 2007). Proponents of this view claim that the motor system is essential for social cognition (Gallese, 2007).

Social and emotional development are intertwined; social interactions with other people and observation of their emotional reactions are of the utmost importance for the development and maturation of emotional competence. An impoverished pattern of social experiences as in ASD will have its consequences for the emotional development of an individual.

Are the observed emotional deficits in subjects with ASD only a consequence of limited normal social experiences, or are they present from the very start and do they contribute to the abnormalities in social interaction? Recent reviews in this field have already suggested that impairments of emotion processing in ASD should not be viewed as a mere consequence of core social deficits, but instead as a result of an interplay between emotion and various cognitive processes as well as social development (Gaigg, 2012; Nuske et al., 2013). The data on emotional deficits in adolescents and adults with ASD indicate that these are not limited to the context of social interaction, but also found in tasks that do not directly rely on social interaction or communication skills, such as memory and attention tasks. However, there is still a possibility that these emotional deficits have been ultimately caused by social deficits that affect the development of the emotional competence and emotion understanding: Because a child with ASD is not able to establish normal social contact, his/her knowledge and experience related to emotions are also limited. One way to clarify this issue is to investigate the development of reciprocal social interaction and the amount of social experience along with the development of emotional competence using a longitudinal design. Such a study design would allow a disentanglement of the mutual influence of social and emotional development. Unfortunately, so far not enough developmental studies are available, and the developmental course of this impairment needs further study. Another approach is to compare the processing of emotion in language to other language aspects that would equally rely on social interaction and social understanding, and to test if emotional language processing is impaired above and beyond general semantic or pragmatic language processing. The stimuli in the studies reviewed here are difficult to separate into social vs. nonsocial types. One can rather speak about the degree to which a task has a social component. For example, having a structured interview or having to explain the meaning of a word to the experimenter can be viewed as a more social task, while listening to recorded speech is less social, and hearing or reading word lists is even less social. None of the studies included in this review manipulated social and emotional aspects of the task independently, although several studies attempted to compare social and emotional aspects of the stimuli (Hobson and Lee, 1989; Beversdorf et al., 1998).

The consideration of social and emotional functioning as rather distinct but closely interacting domains during development has implications for designing and performing longitudinal studies of subjects with ASD. These studies should assess both social and emotional functioning and examine whether and how social problems aggravate problems of emotional functioning, and vice versa in healthy and ASD subjects. Furthermore, research should address whether subjects with ASD try to compensate for their deficit in the processing of social or emotional stimuli by using learned cognitive strategies. In addition, it is important to disentangle the contributions of specific cognitive functions to the problems in the emotional domain and in the social domain to better understand the nature of the disorder and to develop appropriate intervention strategies.

There is also an urgent need for translational cognitive and neuroscience studies in ASD. These should bridge the gap between sophisticated research into cognitive and neural mechanisms in selected and rather small samples of ASD subjects, and observing and analyzing social and emotional functioning in daily life in larger and more representative groups of subjects with ASD. The final test of prospective cognitive and neural markers of ASD is their potential to improve our understanding of day-today functioning and adaptation, and to form a basis for clinical intervention and management.

\section{ACKNOWLEDGMENTS}

This work was supported by the Netherlands Organization for Scientific Research under the Top Talent Donders Graduate School grant 243301-24000246.

\section{REFERENCES}

Adams, C., Green, J., Gilchrist, A., and Cox, A. (2002). Conversational behaviour of children with Asperger syndrome and conduct disorder. J. Child Psychol. Psychiatry 43, 679-690. doi: 10.1111/1469-7610.00056

Adolphs, R. (2002). Recognizing emotion from facial expressions: psychological and neurological mechanisms. Behav. Cogn. Neurosci. Rev. 1, 21-62. doi: 10. 1177/1534582302001001003

Amodio, D. M., and Ratner, K. G. (2011). A memory systems model of implicit social cognition. Curr. Dir. Psychol. Sci. 20, 143-148. doi: 10. $1177 / 0963721411408562$

Anderson, J. E., and Holcomb, P. J. (1995). Auditory and visual semantic priming using different stimulus onset asynchronies: an event-related brain potential study. Psychophysiol 32, 177-190. doi: 10.1111/j.1469-8986.1995.tb0 3310.x

Anderson, A. K., and Phelps, E. A. (2001). Lesions of the human amygdala impair enhanced perception of emotionally salient events. Nature 411, 305-309. doi: 10. $1038 / 35077083$

APA. (2000). Diagnostic and Statistical Manual of Mental Disorders: DSM-IV-TR. Washington, DC: American Psychiatric Publishing, Inc.

APA. (2013). Diagnostic and Statistical Manual of Mental Disorders. 5th Edn. Washington, DC: American Psychiatric Publishing, Inc.

Bagby, R., Taylor, G., and Parker, J. (1994). The Twenty-item Toronto Alexithymia Scale-II. Convergent, discriminant and concurrent validity. J. Psychosom. Res. 38, 33-40. doi: 10.1016/0022-3999(94)90006-x

Bang, J., Burns, J., and Nadig, A. (2012). Brief report: conveying subjective experience in conversation: production of mental state terms and personal narratives in individuals with high functioning autism. J. Autism Dev. Disord. 43, 17321740. doi: 10.1007/s10803-012-1716-4

Bänziger, T., and Scherer, K. R. (2005). The role of intonation in emotional expressions. Speech Communication 46, 252-267. doi: 10.1016/j.specom.2005. 02.016

Barnes, J. L., Lombardo, M. V., Wheelwright, S., and Baron-Cohen, S. (2009). Moral Dilemmas film task: a study of spontaneous narratives by individuals with autism spectrum conditions. Autism Res. 2, 148-156. doi: 10.1002/aur.79

Barsalou, L. W. (2008). Grounded Cognition. Annu. Rev. Psychol. 59, 617-645. doi: 10.1146/annurev.psych.59.103006.093639

Bauminger, N. (2004). The expression and understanding of jealousy in children with autism. Dev. Psychopathol. 16, 157-177. doi: 10.1017/s09545794040 44451 
Begeer, S., Koot, H. M., Rieffe, C., Meerum Terwogt, M., and Stegge, H. (2008). Emotional competence in children with autism: diagnostic criteria and empirical evidence. Dev. Rev. 28, 342-369. doi: 10.1016/j.dr.2007.09.001

Berthoz, S., and Hill, E. L. (2005). The validity of using self-reports to assess emotion regulation abilities in adults with autism spectrum disorder. Eur. Psychiatry 20, 291-298. doi: 10.1016/j.eurpsy.2004.06.013

Beversdorf, D. Q., Anderson, J. M., Manning, S. E., Anderson, S. L., Nordgren, R. E., Felopulos, G. J., et al. (1998). The effect of semantic and emotional context on written recall for verbal language in high functioning adults with autism spectrum disorder. J. Neurol Neurosurg. Psychiatry 65, 685-692. doi: 10. 1136/jnnp.65.5.685

Bird, G., Press, C., and Richardson, D. C. (2011). The Role of Alexithymia in Reduced Eye-Fixation in Autism Spectrum Conditions. J. Autism Dev. Disord. 41, 556-1564. doi: 10.1007/s10803-011-1183-3

Bird, G., Silani, G., Brindley, R., White, S., Frith, U., and Singer, T. (2010). Empathic brain responses in insula are modulated by levels of alexithymia but not autism. Brain 133, 1515-1525. doi: 10.1093/brain/awq060

Bishop, S. L., Richler, J., and Lord, C. (2006). Association between restricted and repetitive behaviors and nonverbal iq in children with autism spectrum disorders. Child Neuropsychol. 12, 247-267. doi: 10.1080/092970406006 30288

Boucher, J., Lewis, V., and Collis, G. M. (2000). Voice processing abilities in children with autism, children with specific language impairments and young typically developing children. J. Child Psychol. Psychiatry 41, 847-857. doi: 10.1111/14697610.00672

Brown, B., Morris, G., Nida, R., and Baker-Ward, L. (2012). Brief report: making experience personal: internal states language in the memory narratives of children with and without Asperger's disorder. J. Autism Dev. Disord. 42, 441446. doi: 10.1007/s10803-011-1246-5

Buitelaar, J. K., van der Wees, M., Swaab-Barneveld, H., and van der Gaag, R. J. (1999). Verbal memory and performance IQ predict theory of mind and emotion recognition ability in children with autistic spectrum disorders and in psychiatric control children. J. Child Psychol. Psychiatry 40, 869-881. doi: 10. 1111/1469-7610.00505

Capps, L., Losh, M., and Thurber, C. (2000). "The frog ate the bug and made his mouth sad": narrative competence in children with autism. J. Abnorm. Child Psychol. 28, 193-204. doi: 10.1023/A:1005126915631

Carr, L., Iacoboni, M., Dubeau, M.-C., Mazziotta, J. C., and Lenzi, G. L. (2003). Neural mechanisms of empathy in humans: a relay from neural systems for imitation to limbic areas. Proc. Natl. Acad. Sci. U S A 100, 5497-5502. doi: 10. 1073/pnas.0935845100

Cato, M. A., Crosson, B., Gökçay, D., Soltysik, D., Wierenga, C., Gopinath, K., et al. (2004). Processing words with emotional connotation: an fmri study of time course and laterality in rostral frontal and retrosplenial cortices. J. Cogn. Neurosci. 16, 167-177. doi: 10.1162/089892904322984481

Chandler, S., Charman, T., Baird, G., Simonoff, E., Loucas, T., Meldrum, D., et al. (2007). Validation of the social communication questionnaire in a population cohort of children with autism spectrum disorders. J. Am. Acad. Child Adolesc. Psychiatry 46, 1324-1332. doi: 10.1097/chi.0b013e31812f7d8d

Corden, B., Chilvers, R., and Skuse, D. (2008). Emotional modulation of perception in Asperger's syndrome. J. Autism Dev. Disord. 38, 1072-1080. doi: 10. 1007/s10803-007-0485-y

Crick, N. R., and Dodge, K. A. (1994). A review and reformulation of social information-processing mechanisms in children's social adjustment. Psychol. Bull. 115, 74-101. doi: 10.1037//0033-2909.115.1.74

Crick, N. R., and Dodge, K. A. (1996). Social information-processing mechanisms in reactive and proactive aggression. Child Dev. 67, 993-1002. doi: 10 $2307 / 1131875$

Dapretto, M., Davies, M. S., Pfeifer, J. H., Scott, A. A., Sigman, M., Bookheimer, S. Y., et al. (2005). Understanding emotions in others: mirror neuron dysfunction in children with autism spectrum disorders. Nat. Neurosci. 9, 28-30. doi: 10. 1038/nn 1611

Dawson, G., Osterling, J., Rinaldi, J., Carver, L., and McPartland, J. (2001). Brief report: recognition memory and stimulus-reward associations: indirect support for the role of ventromedial prefrontal dysfunction in autism. J. Autism Dev. Disord. 31, 337-341. doi: 10.1023/A:1010751404865

Decety, J., and Jackson, P. L. (2004). The functional architecture of human empathy. Behav. Cogn. Neurosci. Rev. 3, 71-100. doi: 10.1177/1534582304267187
Denckla, M. B. (1986). New diagnostic criteria for autism and related behavioral disorders: Guidelines for research protocols. J. Am. Acad. Child Psychiatry 25, 221-224. doi: 10.1016/s0002-7138(09)60229-6

Dichter, G. S., Benning, S. D., Holtzclaw, T. N., and Bodfish, J. W. (2010). Affective modulation of the startle eyeblink and postauricular reflexes in autism spectrum disorder. J. Autism Dev. Disord. 40, 858-869. doi: 10.1007/s10803-0090925-y

Dichter, G. S., Felder, J. N., Green, S. R., Rittenberg, A. M., Sasson, N. J., and Bodfish, J. W. (2012a). Reward circuitry function in autism spectrum disorders. Soc. Cogn. Affect. Neurosci. 7, 160-172. doi: 10.1093/scan/nsq095

Dichter, G. S., Richey, J. A., Rittenberg, A. M., Sabatino, A., and Bodfish, J. W. (2012b). Reward circuitry function in autism during face anticipation and outcomes. J. Autism Dev. Disord. 42, 147-160. doi: 10.1007/s10803-0111221-1

Dolcos, F., LaBar, K. S., and Cabeza, R. (2004). Interaction between the amygdala and the medial temporal lobe memory system predicts better memory for emotional events. Neuron 42, 855-863. doi: 10.1016/s0896-6273(04) 00289-2

Eigsti, I.-M., de Marchena, A. B., Schuh, J. M., and Kelley, E. (2011). Language acquisition in autism spectrum disorders: a developmental review. Res. Autism Spectr. Disord. 5, 681-691. doi: 10.1016/j.rasd.2010.09.001

Eigsti, I.-M., Schuh, J., Mencl, E., Schultz, R. T., and Paul, R. (2012). The neural underpinnings of prosody in autism. Child Neuropsychol. 18, 600-617. doi: 10. 1080/09297049.2011.639757

Eslinger, P. J. (1996). "Conceptualizing, describing and measuring components of executive function: A summary. Attention, memory and executive function," in Attention, memory and executive function, eds G. R. Lyon, and N. A. Krasnegor (Baltimore, MD: Paul H Brookes Publishing), 367-395.

Esser, E., Sutera, S., and Fein, D. (2010). "Autism: Genes, anatomy and behavioral outcome," in Genes, Brain and Development The Neurocognition of Genetic Disorders, ed M. A. Barnes (New York: Cambridge University Press), 19-52.

Fein, D., Pennington, B., Markowitz, P., Braverman, M., and Waterhouse, L. (1986). Toward a neuropsychological model of infantile autism: are the social deficits primary? J. Am. Acad. Child Psychiatry 25, 198-212. doi: 10.1016/s00027138(09)60227-2

Flavell, J. H., Green, F. L., and Flavell, E. R. (2000). Development of Children's Awareness of Their Own Thoughts. J. Cogn. Dev. 1, 97-112. doi: 10. 1207/s15327647jcd0101n_10

Frijda, N. H. (2008). “The Psychologists' Point of View," in Handbook of Emotions, 3rd Edn., eds M. Lewis, J. M. Haviland-Jones and L. F. Barrett (New York: The Guilford Press), 68-87.

Frijda, N. H. (2010). Impulsive action and motivation. Biol. Psychol. 84, 570-579. doi: 10.1016/j.biopsycho.2010.01.005

Gaigg, S. B. (2012). The interplay between emotion and cognition in autism spectrum disorder: implications for developmental theory. Front. Integr. Neurosci. 6:113. doi: 10.3389/fnint.2012.00113

Gaigg, S. B., and Bowler, D. M. (2008). Free recall and forgetting of emotionally arousing words in autism spectrum disorder. Neuropsychologia 46, 2336-2343. doi: 10.1016/j.neuropsychologia.2008.03.008

Gaigg, S. B., and Bowler, D. M. (2009a). Brief report: attenuated emotional suppression of the attentional blink in autism spectrum disorder: another nonsocial abnormality? J. Autism Dev. Disord. 39, 1211-1217. doi: 10.1007/s10803009-0719-2

Gaigg, S. B., and Bowler, D. M. (2009b). Illusory memories of emotionally charged words in autism spectrum disorder: further evidence for atypical emotion processing outside the social domain. J. Autism Dev. Disord. 39, 1031-1038. doi: 10.1007/s10803-009-0710-y

Gallese, V. (2007). Before and below 'theory of mind': embodied simulation and the neural correlates of social cognition. Philos. Trans. R Soc. Lond. B Biol. Sci. 362, 659-669. doi: 10.1098/rstb.2006.2002

Gallese, V., and Sinigaglia, C. (2011). What is so special about embodied simulation? Trends Cogn. Sci. 15, 512-519. doi: 10.1016/j.tics.2011.09.003

Gazzola, V., Aziz-Zadeh, L., and Keysers, C. (2006). Empathy and the Somatotopic Auditory Mirror System in Humans. Curr. Biol. 16, 1824-1829. doi: 10.1016/j. cub.2006.07.072

Goldstein, S. (2002). Review of the asperger syndrome diagnostic scale. J. Autism Dev. Disord. 32, 611-614. doi: 10.1023/A:1021215300163 
Greenwald, A. G., and Banaji, M. R. (1995). Implicit social cognition: attitudes, self-esteem and stereotypes. Psychol. Rev. 102, 4-27. doi: 10.1037/0033-295x. 102.1.4

Groen, W. B., Zwiers, M. P., van der Gaag, R. J., and Buitelaar, J. K. (2008). The phenotype and neural correlates of language in autism: an integrative review. Neurosci. Biobehav. Rev. 32, 1416-1425. doi: 10.1016/j.neubiorev.2008.05.008

Grossman, R. B., Bemis, R. H., Skwerer, D. P., and Tager-Flusberg, H. (2010). Lexical and affective prosody in children with high-functioning autism. J. Speech Lang. Hear. Res. 53, 778-793. doi: 10.1044/1092-4388(2009/08-0127)

Hadjikhani, N., Joseph, R. M., Snyder, J., and Tager-Flusberg, H. (2006). Anatomical differences in the mirror neuron system and social cognition network in autism. Cereb. Cortex 16, 1276-1282. doi: 10.1093/cercor/bhj069

Hamilton, A. F. D. C., Brindley, R. M., and Frith, U. (2007). Imitation and action understanding in autistic spectrum disorders: how valid is the hypothesis of a deficit in the mirror neuron system? Neuropsychologia 45, 1859-1868. doi: 10. 1016/j.neuropsychologia.2006.11.022

Han, D. H., Yoo, H. J., Kim, B. N., McMahon, W., and Renshaw, P. F. (2014). Brain activity of adolescents with high functioning autism in response to emotional words and facial emoticons. PLOS ONE 9:e91214. doi: 10.1371/journal.pone. 0091214

Happé, F. G. E. (1997). Central coherence and theory of mind in autism: reading homographs in context. Br. J. Dev. Psychol. 15, 1-12. doi: 10.1111/j.2044-835x. 1997.tb00721.x

Happé F. G. E. (2000). "Parts and wholes, meaning and minds: Central coherence and its relation to theory of mind," in Understanding Other Minds: Perspectives from Autism and Developmental Cognitive Neuroscience, eds S. Baron-Cohen, H. Tager-Flusberg and D. Cohen (Oxford: Oxford University Press), 203-221.

Happé, F. G. E. (2005). “The Weak Central Coherence Account of Autism,” in Handbook of Autism and Pervasive Developmental Disorders: Diagnosis, Development, Neurobiology and Behavior (Vol. 1), eds F. R. Volkmar, R. Paul, A. Klin and D. J. Cohen (Hoboken, NJ: John Wiley \& Sons, Inc.), 640-649.

Happé, F. G. E., and Frith, U. (2006). The weak coherence account: detail-focused cognitive style in autism spectrum disorders. J. Autism Dev. Disord. 36, 5-25. doi: 10.1007/s10803-005-0039-0

Harms, M. B., Martin, A., and Wallace, G. L. (2010). Facial emotion recognition in autism spectrum disorders: a review of behavioral and neuroimaging studies. Neuropsychol. Rev. 20, 290-322. doi: 10.1007/s11065-010-9138-6

Hesling, I., Dilharreguy, B., Peppé, S., Amirault, M., Bouvard, M., and Allard, M. (2010). The integration of prosodic speech in high functioning autism: a preliminary fMRI study. PLOS ONE 5:e11571. doi: 10.1371/journal.pone. 0011571

Hill, E. L., Berthoz, S., and Frith, U. (2004). Brief report: cognitive processing of own emotions in individuals with autistic spectrum disorder and in their relatives. J. Autism Dev. Disord. 34, 229-235. doi: 10.1023/b:jadd.0000022613. 41399.14

Hillier, A., and Allinson, L. (2002). Understanding embarrassment among those with autism: breaking down the complex emotion of embarrassment among those with autism. J. Autism Dev. Disord. 32, 583-592. doi: 10. 1023/A:1021259115185

Hobson, R. P. (1991). Methodological issues for experiments on autistic individuals' perception and understanding of emotion. J. Child Psychol. Psychiatry 32, 1135-1158. doi: 10.1111/j.1469-7610.1991.tb00354.x

Hobson, R. P., and Lee, A. (1989). Emotion-Related and abstract concepts in autistic people: evidence from the british picture vocabulary scale. J. Autism Dev. Disord. 19, 601-623. doi: 10.1007/bf02212860

Holcomb, P. J., Coffey, S. A., and Neville, H. J. (1992). Visual and auditory sentence processing: a developmental analysis using event-related brain potentials. Dev. Neuropsychol. 8, 203-241. doi: 10.1080/87565649209540525

Holcomb, P. J., and Neville, H. J. (1990). Auditory and visual semantic priming in lexical decision: a comparison using event-related brain potentials. Lang. Cogn. Process 5, 281-312. doi: 10.1080/01690969008407065

Hudry, K., Leadbitter, K., Temple, K., Slonims, V., McConachie, H., Aldred, C., et al. (2010a). Preschoolers with autism show greater impairment in receptive compared with expressive language abilities. Int. J. Lang. Commun. Disord. 45, 681-690. doi: 10.3109/13682820903461493

Hudry, K., Leadbitter, K., Temple, K., Slonims, V., McConachie, H., Aldred, C., et al. (2010b). Preschoolers with autism show greater impairment in receptive compared with expressive language abilities. Int. J. Lang. Commun. Disord. 45, 681-690. doi: 10.3109/13682820903461493
Iacoboni, M., and Dapretto, M. (2006). The mirror neuron system and the consequences of its dysfunction. Nat. Rev. Neurosci. 7, 942-951. doi: 10.1038/nrn2024

Jabbi, M., and Keysers, C. (2008). Inferior frontal gyrus activity triggers anterior insula response to emotional facial expressions. Emotion 8, 775-780. doi: 10. 1037/a0014194

Jabbi, M., Swart, M., and Keysers, C. (2007). Empathy for positive and negative emotions in the gustatory cortex. NeuroImage 34, 1744-1753. doi: 10.1016/j. neuroimage.2006.10.032

Jarrold, C., Boucher, J., and Russell, J. (1997). Language profiles in children with autism: theoretical and methodological implications. Autism 1, 57-76. doi: 10 . $1177 / 1362361397011007$

Jarrold, C., Butler, D. W., Cottington, E. M., and Jimenez, F. (2000). Linking theory of mind and central coherence bias in autism and in the general population. Dev. Psychol. 36, 126-138. doi: 10.1037//0012-1649.36.1.126

Järvinen-Pasley, A., Peppé, S., King-Smith, G., and Heaton, P. (2008). The relationship between form and function level receptive prosodic abilities in autism. J. Autism Dev. Disord. 38, 1328-1340. doi: 10.1007/s10803-007-0520-z

Jemel, B., Mottron, L., and Dawson, M. (2006). Impaired face processing in autism: fact or artifact? J. Autism Dev. Disord. 36, 91-106. doi: 10.1007/s10803-0050050-5

Jones, A. P., Happé, F. G. E., Gilbert, F., Burnett, S., and Viding, E. (2010). Feeling, caring, knowing: different types of empathy deficit in boys with psychopathic tendencies and autism spectrum disorder. J. Child Psychol. Psychiatry 51, 11881197. doi: 10.1111/j.1469-7610.2010.02280.x

Kana, R. K., Wadsworth, H. M., and Travers, B. G. (2011). A systems level analysis of the mirror neuron hypothesis and imitation impairments in autism spectrum disorders. Neurosci. Biobehav. Rev. 35, 894-902. doi: 10.1016/j.neubiorev.2010. 10.007

Kanner, L. (1943). Autistic disturbances of affective contact. Nervous Child 2, 217 250.

Kennedy, D. P., Redcay, E., and Courchesne, E. (2006). Failing to deactivate: resting functional abnormalities in autism. Proc. Natl. Acad. Sci. U S A 103, 8275-8280. doi: 10.1073/pnas.0600674103

Keysers, C., and Gazzola, V. (2006). Towards a unifying neural theory of social cognition. Prog. Brain Res. 156, 379-401. doi: 10.1016/s0079-6123(06)56021-2

Kohls, G., Peltzer, J., Schulte-Rüther, M., Kamp-Becker, I., Remschmidt, H., Herpertz-Dahlmann, B., et al. (2011). Atypical brain responses to reward cues in autism as revealed by event-related potentials. J. Autism Dev. Disord. 41, 15231533. doi: 10.1007/s10803-011-1177-1

Kohls, G., Schulte-Ruether, M., Nehrkorn, B., Mueller, K., Fink, G. R., KampBecker, I., et al. (2013). Reward system dysfunction in autism spectrum disorders. Soc. Cogn. Affect Neurosci. 8, 565-572. doi: 10.1093/scan/nss033

Korpilahti, P., Jansson-Verkasalo, E., Mattila, M.-L., Kuusikko, S., Suominen, K., Rytky, S., et al. (2007). Processing of affective speech prosody is impaired in asperger syndrome. J. Autism Dev. Disord. 37, 1539-1549. doi: 10.1007/s10803006-0271-2

Kuchinke, L., Schneider, D., Kotz, S. A., and Jacobs, A. M. (2011). Spontaneous but not explicit processing of positive sentences impaired in asperger's syndrome: pupillometric evidence. Neuropsychologia 49, 331-338. doi: 10.1016/j. neuropsychologia.2010.12.026

Kushki, A., Drumm, E., Mobarak, M. P., Tanel, N., Dupuis, A., Chau, T., et al. (2013). Investigating the autonomic nervous system response to anxiety in children with autism spectrum disorders. PLoS ONE 8:e59730. doi: 10.1371/journal. pone. 0059730

Larsen, J. T., Berntson, G. G., Poehlmann, K. M., Ito, T. A., and Cacioppo, J. T. (2008). "The Psychophysiology of Emotion," in Handbook of Emotions, 3rd Edn., eds M. Lewis, J. M. Haviland-Jones and L. F. Barrett (New York: The Guilford Press), 180-195.

Larson, M. J., South, M., Krauskopf, E., Clawson, A., and Crowley, M. J. (2011). Feedback and reward processing in high-functioning autism. Psychiatry Res. 187, 198-203. doi: 10.1016/j.psychres.2010.11.006

Lee, S. J., Lee, H.-K., Kweon, Y.-S., Lee, C. T., and Lee, K.-U. (2009). The impact of executive function on emotion recognition and emotion experience in patients with schizophrenia. Psychiatry Investig. 6, 156-162. doi: 10.4306/pi.2009.6.3.156

Leudar, I., Costall, A., and Francis, D. (2004). Theory of mind: a critical assessment. Theory Psychol. 14, 571-578. doi: 10.1177/0959354304046173

Linden, W., Wen, F., and Paulhus, D. L. (1995). "Measuring alexithymia: Reliability, validity and prevalence," in Advances in personality assessment, eds J. Butcher and C. Spielberger (Hillsdale, NJ: Earlbaum), 51-95. 
Lindner, J. L., and Rosén, L. A. (2006). Decoding of emotion through facial expression, prosody and verbal content in children and adolescents with asperger's syndrome. J. Autism Dev. Disord. 36, 769-777. doi: 10.1007/s10803-0060105-2

Lombardo, M. V., Barnes, J. L., Wheelwright, S. J., and Baron-Cohen, S. (2007). Self-referential cognition and empathy in autism. PLOS ONE 2:e883. doi: 10. 1371/journal.pone.0000883

Losh, M., and Capps, L. (2006). Understanding of emotional experience in autism: insights from the personal accounts of high-functioning children with autism. Dev. Psychol. 42, 809-818. doi: 10.1037/0012-1649.42.5.809

Maddock, R. J., Garrett, A. S., and Buonocore, M. H. (2003). Posterior cingulate cortex activation by emotional words: fMRI evidence from a valence decision task. Hum. Brain Mapp. 18, 30-41. doi: 10.1002/hbm.10075

Mason, R. A., Williams, D. L., Kana, R. K., Minshew, N., and Just, M. A. (2008). Theory of mind disruption and recruitment of the right hemisphere during narrative comprehension in autism. Neuropsychologia 46, 269-280. doi: 10. 1016/j.neuropsychologia.2007.07.018

Matson, J. L., and Shoemaker, M. (2009). Intellectual disability and its relationship to autism spectrum disorders. Res. Dev. Disabil. 30, 1107-1114. doi: 10.1016/j. ridd.2009.06.003

McClure, E. B. (2000). A Meta-Analytic Review of Sex Differences in Facial Expression Processing and Their Development in Infants, Children and Adolescents. Psychol. Bull. 126, 424-453. doi: 10.1037/0033-2909.126.3.424

McDonald, S., Hunt, C., Henry, J. D., Dimoska, A., and Bornhofen, C. (2010). Angry responses to emotional events: The role of impaired control and drive in people with severe traumatic brain injury. J. Clin. Exp. Neuropsychol. 32, 855864. doi: 10.1080/13803391003596405

Mesquita, B., and Frijda, N. H. (2011). An emotion perspective on emotion regulation. Cogn. Emot. 25, 782-784. doi: 10.1080/02699931.2011. 586824

Miniscalco, C., Fränberg, J., Schachinger-Lorentzon, U., and Gillberg, C. (2012). Meaning what you say? Comprehension and word production skills in young children with autism. Res. Autism Spectr. Disord. 6, 204-211. doi: 10.1016/j.rasd. 2011.05.001

Mottron, L., and Burack, J. A. (2001). "Enhanced perceptual functioning in the development of autism," in The Development of Autism: Perspectives from Theory and Research, eds J. A. Burack, T. Charman, N. Yirmiya and P. R. Zelazo (Mahwah, NJ: Lawrence Erlbaum Associates Publishers), 131-148.

Mottron, L., Dawson, M., Soulières, I., Hubert, B., and Burack, J. (2006). Enhanced Perceptual Functioning in Autism: An Update and Eight Principles of Autistic Perception. J. Autism Dev. Disord. 36, 27-43. doi: 10.1007/s10803-005-0040-7

Mueller, S. C. (2011). The influence of emotion on cognitive control: relevance for development and adolescent psychopathology. Front. Psychol. 2:327. doi: 10. 3389/fpsyg.2011.00327

Müller, E., and Schuler, A. (2006). Verbal Marking of Affect by Children with Asperger Syndrome and High Functioning Autism during Spontaneous Interactions with Family Members. J. Autism Dev. Disord. 36, 1089-1100. doi: 10. 1007/s10803-006-0146-6

Nemiah, J. C. (1977). Alexithymia: Theoretical considerations. Psychother. Psychosom. 28, 199-206. doi: 10.1159/000287064

Neumann, D., Spezio, M. L., Piven, J., and Adolphs, R. (2006). Looking you in the mouth: abnormal gaze in autism resulting from impaired top-down modulation of visual attention. Soc. Cogn. Affect. Neurosci. 1, 194-202. doi: 10. 1093/scan/ns1030

Niznikiewicz, M. A., O’Donnell, B. F., Nestor, P. G., Smith, L., Law, S., Karapelou, M., et al. (1997). ERP assessment of visual and auditory language processing in schizophrenia. J. Abnorm. Psychol. 106, 85-94. doi: 10.1037//0021-843x. 106.1.85

Nuske, H. J., Vivanti, G., and Dissanayake, C. (2013). Are emotion impairments unique to, universal, or specific in autism spectrum disorder? A comprehensive review. Cogn. Emot. 27, 1042-1061. doi: 10.1080/02699931.2012.762900

Ozonoff, S., South, M., and Provencal, S. (2005). "Executive Functions," in Handbook of Autism and Pervasive Developmental Disorders: Diagnosis, Development, Neurobiology and Behavior (Vol. 1), eds F. R. Volkmar, R. Paul, A. Klin and D. J. Cohen (Hoboken, NJ: John Wiley \& Sons, Inc.), 606-627.

Pearlman-Avnion, S., and Eviatar, Z. (2002). Narrative analysis in developmental social and linguistic pathologies: dissociation between emotional and informational language use. Brain Cogn. 48, 494-499. doi: 10.1006/brcg.2001.1401
Peppé, S., McCann, J., Gibbon, F., O’Hare, A., and Rutherford, M. (2007). Receptive and Expressive Prosodic Ability in Children With High-Functioning Autism. J. Speech Lang. Hear. Res. 50, 1015-1028. doi: 10.1044/1092-4388 (2007/071)

Perry, A., Troje, N. F., and Bentin, S. (2010). Exploring motor system contributions to the perception of social information: Evidence from EEG activity in the mu/alpha frequency range. Soc. Neurosci. 5, 272-284. doi: 10. 1080/17470910903395767

Pessoa, L. (2009). How do emotion and motivation direct executive control? Trends Cogn. Sci. 13, 160-166. doi: 10.1016/j.tics.2009.01.006

Pfeifer, J. H., Iacoboni, M., Mazziotta, J. C., and Dapretto, M. (2008). Mirroring others' emotions relates to empathy and interpersonal competence in children. Neuroimage 39, 2076-2085. doi: 10.1016/j.neuroimage.2007.10.032

Rellini, E., Tortolani, D., Trillo, S., Carbone, S., and Montecchi, F. (2004). Childhood Autism Rating Scale (CARS) and Autism Behavior Checklist (ABC) Correspondence and Conflicts with DSM-IV Criteria in Diagnosis of Autism. J. Autism Dev. Disord. 34, 703-708. doi: 10.1007/s10803-0045290-2

Rieffe, C., Meerum Terwogt, M., and Kotronopoulou, K. (2007). Awareness of Single and Multiple Emotions in High-functioning Children with Autism. J. Autism Dev. Disord. 37, 455-465. doi: 10.1007/s10803-006-0171-5

Ritvo, E. R., and Freeman, B. J. (1977). National Society for Autistic Children Definition of the Syndrome of Autism. J. Pediatr. Psychol. 2, 146-148. doi: 10. 1093/jpepsy/2.4.146

Rutter, M. (1978). Diagnosis and definition of childhood autism. J. Autism. Child Schizophr. 8, 139-161. doi: 10.1007/bf01537863

Saarela, M. V., Hlushchuk, Y., Williams, A. C. D. C., Schürmann, M., Kalso, E., and Hari, R. (2007). The Compassionate Brain: Humans Detect Intensity of Pain from Another's Face. Cereb. Cortex 17, 230-237. doi: 10.1093/cercor/ bhj141

Salminen, J. K., Saarijärvi, S., Äärelä, E., Toikka, T., and Kauhanen, J. (1999). Prevalence of alexithymia and its association with sociodemographic variables in the general population of Finland. J. Psychosom. Res. 46, 75-82. doi: 10. 1016/s0022-3999(98)00053-1

Schmitz, N., Rubia, K., van Amelsvoort, T., Daly, E., Smith, A., and Murphy, D. G. M. (2008). Neural correlates of reward in autism. Br. J. Psychiatry 192, 19-24. doi: 10.1192/bjp.bp.107.036921

Schopler, E., Reichler, R., DeVellis, R., and Daly, K. (1980). Toward objective classification of childhood autism: childhood Autism Rating Scale (CARS). J. Autism Dev. Disord. 10, 91-103. doi: 10.1007/bf02408436

Schulte-Rüther, M., Greimel, E., Markowitsch, H. J., Kamp-Becker, I., Remschmidt, H., Fink, G. R., et al. (2011). Dysfunctions in brain networks supporting empathy: An fMRI study in adults with autism spectrum disorders. Soc. Neurosci. 6, 1-21. doi: 10.1080/17470911003708032

Scott-Van Zeeland, A. A., Dapretto, M., Ghahremani, D. G., Poldrack, R. A., and Bookheimer, S. Y. (2010). Reward processing in autism. Autism Res. 3, 53-67. doi: 10.1186/2040-2392-3-7

Seeley, W. W., Menon, V., Schatzberg, A. F., Keller, J., Glover, G. H., Kenna, H., et al. (2007). Dissociable Intrinsic Connectivity Networks for Salience Processing and Executive Control. J. Neurosci. 27, 2349-2356. doi: 10.1523/jneurosci.5587-06. 2007

Senju, A., and Johnson, M. H. (2009). Atypical eye contact in autism: Models, mechanisms and development. Neurosci. Biobehav. Rev. 33, 1204-1214. doi: 10. 1016/j.neubiorev.2009.06.001

Shamay-Tsoory, S. G., Aharon-Peretz, J., and Perry, D. (2009). Two systems for empathy: a double dissociation between emotional and cognitive empathy in inferior frontal gyrus versus ventromedial prefrontal lesions. Brain 132, 617627. doi: 10.1093/brain/awn279

Silani, G., Bird, G., Brindley, R., Singer, T., Frith, C., and Frith, U. (2008). Levels of emotional awareness and autism: an fMRI study. Soc. Neurosci. 3, 97-112. doi: 10.1080/17470910701577020

Siller, M., Swanson, M. R., Serlin, G., and Teachworth, A. G. (2014). Internal state language in the storybook narratives of children with and without autism spectrum disorder: investigating relations to theory of mind abilities. Res. Autism Spectr. Disord. 8, 589-596. doi: 10.1016/j.rasd.2014. 02.002

Sinigaglia, C., and Sparaci, L. (2010). Emotions in action through the looking glass. J. Anal. Psychol. 55, 3-29. doi: 10.1111/j.1468-5922.2009.01821.x 
Sodian, B., and Kristen, S. (2010). "Theory of mind," in Towards a Theory of Thinking, eds B. M. Glatzeder, V. Goel and A. von Muller (Berlin Heidelberg: Springer-Verlag), 189-201.

South, M., Ozonoff, S., Suchy, Y., Kesner, R. P., McMahon, W. M., and Lainhart, J. E. (2008). Intact emotion facilitation for nonsocial stimuli in autism: Is amygdala impairment in autism specific for social information? J. Int. Neuropsychol. Soc. 14, 42-54. doi: 10.1017/s1355617708080107

Tager-Flusberg, H. (1992). Autistic children's talk about psychological states: deficits in the early acquisition of a theory of mind. Child Dev. 63, 161-172. doi: $10.2307 / 1130910$

Tager-Flusberg, H., Paul, R., and Lord, C. (2005). "Language and Communication in Autism," in Handbook of Autism and Pervasive Developmental Disorders, eds F. R. Volkmar, R. Paul, A. Klin and D. Cohen (Hoboken, NJ: Wiley), 335-364.

Thoma, P., Zalewski, I., von Reventlow, H. G., Norra, C., Juckel, G., and Daum, I. (2011). Cognitive and affective empathy in depression linked to executive control. Psychiatry Res. 189, 373-378. doi: 10.1016/j.psychres.2011. 07.030

Uddin, L. Q., Iacoboni, M., Lange, C., and Keenan, J. P. (2007). The self and social cognition: the role of cortical midline structures and mirror neurons. Trends Cogn. Sci. 11, 153-157. doi: 10.1016/j.tics.2007.01.001

Uljarevic, M., and Hamilton, A. (2013). Recognition of emotions in autism: a formal meta-analysis. J. Autism Dev. Disord. 43, 1517-1526. doi: 10.1007/s10803012-1695-5

Volden, J., and Sorenson, A. (2009). Bossy and nice requests: Varying language register in speakers with autism spectrum disorder (ASD). J. Commun. Disord. 42, 58-73. doi: 10.1016/j.jcomdis.2008.08.003

Volkmar, F., Cicchetti, D., Dykens, E., Sparrow, S., Leckman, J., and Cohen, D. (1988). An evaluation of the autism behavior checklist. J. Autism Dev. Disord. 18, 81-97. doi: 10.1007/bf02211820

Wilbarger, J. L., McIntosh, D. N., and Winkielman, P. (2009). Startle modulation in autism: Positive affective stimuli enhance startle response. Neuropsychologia 47, 1323-1331. doi: 10.1016/j.neuropsychologia.2009.01.025

Willcutt, E. G., Doyle, A. E., Nigg, J. T., Faraone, S. V., and Pennington, B. F. (2005). Validity of the executive function theory of attention-deficit/hyperactivity disorder: a meta-analytic review. Biol. Psychiatry 57, 1336-1346. doi: 10.1016/j. biopsych.2005.02.006

Williams, D., Botting, N., and Boucher, J. (2008). Language in Autism and Specific Language Impairment: Where Are the Links? Psychol Bull 134, 944-963. doi: 10. 1037/a0013743

Williams, D., and Happé, F. (2010). Recognising 'social' and 'non-social' emotions in self and others: a study of autism. Autism 14, 285-304. doi: 10. $1177 / 1362361309344849$

Wolf, J. M., Tanaka, J. W., Klaiman, C., Cockburn, J., Herlihy, L., Brown, C., et al. (2008). Specific impairment of face-processing abilities in children with autism spectrum disorder using the Let's Face It! skills battery. Autism Res. 1, 329-340. doi: 10.1002/aur.56

Wolpert, D. M., Doya, K., and Kawato, M. (2003). A unifying computational framework for motor control and social interaction. Philos. Trans. R. Soc. Lond. B Biol. Sci. 358, 593-602. doi: 10.1098/rstb.2002.1238

Yirmiya, N., Sigman, M. D., Kasari, C., and Mundy, P. (1992). Empathy and cognition in high-functioning children with autism. Child Dev. 63, 150-160. doi: $10.2307 / 1130909$

Conflict of Interest Statement: The authors declare that the research was conducted in the absence of any commercial or financial relationships that could be construed as a potential conflict of interest.

Received: 04 July 2014; accepted: 20 November 2014; published online: 06 January 2015.

Citation: Lartseva A, Dijkstra T and Buitelaar JK (2015) Emotional language processing in autism spectrum disorders: a systematic review. Front. Hum. Neurosci. 8:991. doi: 10.3389/fnhum.2014.00991

This article was submitted to the journal Frontiers in Human Neuroscience.

Copyright (c) 2015 Lartseva, Dijkstra and Buitelaar. This is an open-access article distributed under the terms of the Creative Commons Attribution License (CC BY). The use, distribution and reproduction in other forums is permitted, provided the original author(s) or licensor are credited and that the original publication in this journal is cited, in accordance with accepted academic practice. No use, distribution or reproduction is permitted which does not comply with these terms. 